\title{
SOEP
}

SOEPpapers

SOEPnanoers
on Multidisciplinary Panel Data Research

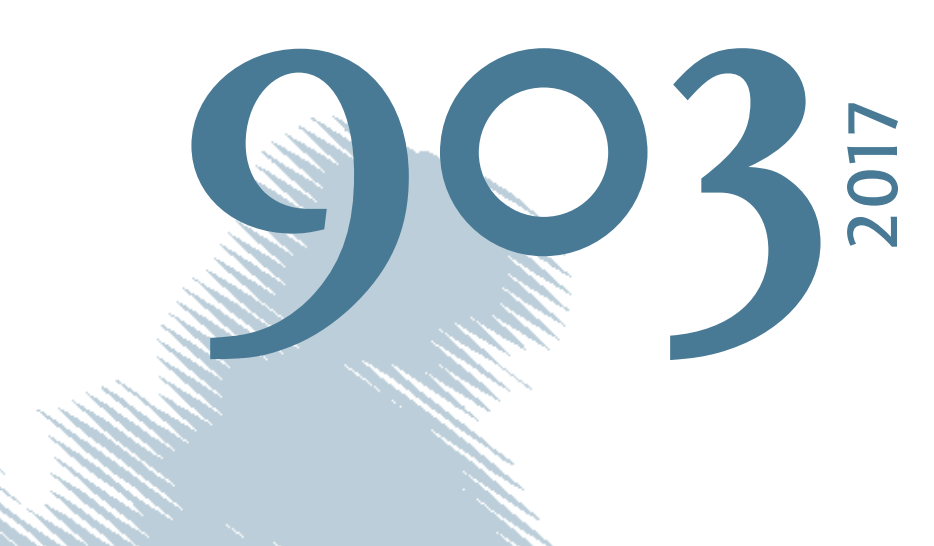

\section{Can Raising Instructional Time Crowd Out Student Pro-Social Behaviour? Evidence From Germany}


This series presents research findings based either directly on data from the German SocioEconomic Panel study (SOEP) or using SOEP data as part of an internationally comparable data set (e.g. CNEF, ECHP, LIS, LWS, CHER/PACO). SOEP is a truly multidisciplinary household panel study covering a wide range of social and behavioral sciences: economics, sociology, psychology, survey methodology, econometrics and applied statistics, educational science, political science, public health, behavioral genetics, demography, geography, and sport science.

The decision to publish a submission in SOEPpapers is made by a board of editors chosen by the DIW Berlin to represent the wide range of disciplines covered by SOEP. There is no external referee process and papers are either accepted or rejected without revision. Papers appear in this series as works in progress and may also appear elsewhere. They often represent preliminary studies and are circulated to encourage discussion. Citation of such a paper should account for its provisional character. A revised version may be requested from the author directly.

Any opinions expressed in this series are those of the author(s) and not those of DIW Berlin. Research disseminated by DIW Berlin may include views on public policy issues, but the institute itself takes no institutional policy positions.

The SOEPpapers are available at http://www.diw.de/soeppapers

\section{Editors:}

Jan Goebel (Spatial Economics)

Martin Kroh (Political Science, Survey Methodology)

Carsten Schröder (Public Economics)

Jürgen Schupp (Sociology)

Conchita D'Ambrosio (Public Economics, DIW Research Fellow)

Denis Gerstorf (Psychology, DIW Research Director)

Elke Holst (Gender Studies, DIW Research Director)

Frauke Kreuter (Survey Methodology, DIW Research Fellow)

Frieder R. Lang (Psychology, DIW Research Fellow)

Jörg-Peter Schräpler (Survey Methodology, DIW Research Fellow)

Thomas Siedler (Empirical Economics, DIW Research Fellow)

C. Katharina Spieß (Education and Family Economics)

Gert G. Wagner (Social Sciences)

ISSN: 1864-6689 (online)

German Socio-Economic Panel (SOEP)

DIW Berlin

Mohrenstrasse 58

10117 Berlin, Germany

Contact: soeppapers@diw.de

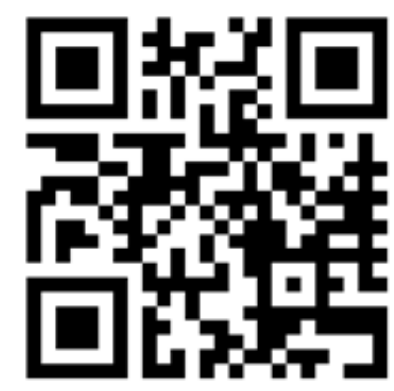




\title{
Can Raising Instructional Time Crowd Out Student Pro-Social Behaviour? \\ Evidence From Germany
}

\author{
Christian Krekel \\ info@christiankrekel.de \\ http: //www. christiankrekel. de \\ Paris School of Economics, \\ 48 Boulevard Jourdan, 75014 Paris, France \\ London School of Economics and Political Science, \\ Houghton Street, London WC2A 2AE, UK \\ German Institute for Economic Research, \\ Mohrenstraße 58, 10117 Berlin, Germany
}

\begin{abstract}
We study whether raising instructional time can crowd out student pro-social behaviour. To this end, we exploit a large educational reform in Germany that has raised weekly instructional time for high school students by $12.5 \%$ as a quasi-natural experiment. We find that this rise has a negative and sizeable effect on volunteering, both at the intensive and at the extensive margin. It also affects political interest. There is no similar crowding out of scholastic involvement, but no substitution either. We conclude that instructional time plays an important role in shaping student pro-social behaviour.
\end{abstract}

Keywords:

Instructional Time, Student Pro-Social Behaviour, Volunteering, Scholastic Involvement, Political Interest, Quasi-Natural Experiment, "G8" Reform, SOEP $J E L$ :

I21, I28, D01 


\section{Introduction}

A growing body of empirical literature documents the importance of instructional time for student learning and performance (Patall et al., 2010). Raising instructional time - the allocated number of hours per year that students spend in formal classroom settings - is often found to have positive effects on cognitive skills such as maths and language ability (Bellei, 2009; Cortes and Goodman, 2014; Taylor, 2014), as well as standardised maths, reading, and scientific literacy test scores Andrietti, 2016; Cattaneo et al. 2016; Huebener et al., 2016). 1] Differences in instructional time between countries are also found to account for some of the observed international gaps in student achievement (Lavy, 2015; Woessmann, 2003).2 Thus, despite being a relative costly input into the educational production function, raising instructional time features high on the policy agenda in many countries (OECD, 2016). Yet, outcomes other than student learning and achievement have scarcely been studied (Patall et al. 2010), and particularly little is known about how changes in instructional time might influence student leisure activities and behaviours. Can raising instructional time have hidden costs by - unintentionally - crowding out student leisure activities and behaviours that parents, educators, and policy-makers alike would otherwise consider worth promoting?

\footnotetext{
${ }^{1}$ There is growing evidence that the effect of raising instructional time on student learning and performance is heterogeneous, and in particular, that higher-performing students tend to benefit relatively more (Cattaneo et al. 2016 , Huebener et al. 2016 .

${ }^{2}$ The importance of instructional time for student achievement varies between educational systems, and in particular, between developed and developing countries (Woessmann, 2016), pointing towards potentially important complementarities in educational production, for example, between instructional time and teacher quality or effective classroom management techniques (Rivkin and Schiman, 2015).
} 
In this paper, we are interested in a particular type of student behaviour: prosocial behaviour, defined as voluntary behaviour intended to benefit one or more individuals other than oneself (Eisenberg et al., 2013). This type of behaviour can cover a broad range of actions such as helping, sharing, and other forms of cooperation (Batson and Powell, 2003), and is distinct from altruism in that it is not purely motivated by increasing another individual's welfare, but can be motivated by, for example, empathy or reciprocity. Pro-social behaviour, and in particular volunteering, is linked to various positive outcomes: at the societal level, it can help build social capital through fostering cooperation and trust and through promoting citizenship (Putnam, 2000); at the individual level, it is found to nurture important cognitive and non-cognitive skills that can improve individual labour market outcomes, to have positive physical and mental health benefits, and to raise subjective well-being over and beyond other benefits (Wilson and Musick, 2012). Specifically for youth, there is evidence that volunteering from an early age on enhances psychological development by raising self-esteem and self-confidence and by discouraging risky behaviours (Hart et al., 2007; Wilson and Musick, 2012).

To study the effect of raising instructional time on student pro-social behaviour, we exploit a large educational reform in Germany as a quasi-natural experiment: starting with school cohorts in the early 2000s, the number of school years required to obtain the university entrance qualification has been reduced from 13 to $12 \mathrm{~S}^{3}$ It

\footnotetext{
${ }^{3}$ In Germany, secondary education, which is compulsory until the age of 16 , is tripartite: after joint primary education, students are tracked into different school types according to their abilities: lower, intermediate, or upper track schools. Some federal states offer schools that combine the lower and intermediate track, or comprehensive schools or alternative school types that postpone tracking. In any case, only the upper track leads to the university entrance qualification. For the
} 
aimed at reducing the graduation age of high school students, which was high in international comparison, to enable an earlier entry into the labour market. This, in turn, aimed at counteracting demographic change, especially an eroding contributor base and a shortage of skilled labour.

This reform - commonly referred to as "G8" reform - has two features that make it particularly interesting for us: first, the overall curriculum and thus total instructional time required to obtain the university entrance qualification has not changed, which, in turn, has lead to a $12.5 \%$ rise in weekly instructional hours across all subjects plus a rise in accompanying coursework $t^{4}$ Specifically, there have been no changes to the taught curriculum that target pro-social behaviour. In terms of an educational production function, this means that learning intensity has increased, whereas other inputs such as class size, instructional materials, and teacher quality have not been changed as a result of the reform. This allows estimating the "pure" effect of raising instructional time on student pro-social behaviour, excluding potentially confounding changes to the educational system that are typically accompanied by similar reforms. Second, since education in Germany is the responsibility of the 16 federal states, there has been a staggered implementation of the reform: while some federal states implemented it as early as 2001 (Saarland), others waited until

sake of brevity, we use the terms high schools and high school students, respectively, to refer to schools and students in the upper track.

${ }^{4}$ Starting from the fifth grade, students generally have to complete at least 265 year-week hours before being allowed to take the university entrance qualification exam (Standing Conference of the Ministers of Education and Cultural Affairs, 2016). Thus, average instruction hours per year increased from 1,051 to 1,184, compared to 950 in upper secondary education in England and 1,038 in the US (OECD, 2014). The rise in weekly instructional hours can be calculated as $(((265 /(12-$ $4)) /(265 /(13-4)))-1) \times 100$. 
2007 (Schleswig-Holstein); yet others have never fully implemented it (RhinelandPalatine), or as in case of Saxony and Thuringia, have always required only 12 school years to obtain the university entrance qualification (Standing Conference of the Ministers of Education and Cultural Affairs, 2016). This allows estimating the causal effect of raising instructional time on student pro-social behaviour by exploiting variation in the implementation of the reform.

Figure A.1 shows this variation across federal states and school cohorts. It also shows the share of students in the different tracks: in school year 2013/14, of $5,187,960$ students in total, $2,329,990(45 \%)$ are in the upper track; with few exceptions, they make up the largest share of students in each federal state.

\section{Figure A.1 about here}

Using survey data on youth and adolescents from the German Socio-Economic Panel Study (SOEP) and a difference-in-differences approach, we find that the $12.5 \%$ rise in weekly instructional time significantly crowds out student pro-social behaviour: it has a negative and sizeable effect on volunteering, decreasing the likelihood to volunteer at least once a month by about six percentage points. Given that almost 34 percent of students report to volunteer at least monthly, this amounts to a decrease of about 18 percent in this share. In other words, the rise in instructional time leads almost every fifth student to change her behaviour from volunteering at least monthly to volunteering less often or not at all. This change is primarily driven by students that report to volunteer on a weekly basis, and it affects both the intensive and extensive margin of volunteering: while half of the students cut back on 
their activities, the other half give them up completely. Students with lower educated parents are up to three times more likely to cut back on their activities. We find no similar crowding out of scholastic involvement, but no substitution either. Interestingly, we find that the rise in instructional time has a differential impact on student political interest: it leads to a depolarisation at both ends of the spectrum, decreasing the share of students that report to be at least fairly interested in politics while at the same time decreasing the share that report to be not interested at all. The size of these changes is very strong: every third student switches category. The results are robust to a different model specification, time trends, and seasonal variation; selection and implementation; and potentially confounding other reforms that are implemented during the observation period. They also withstand a series of placebo tests. We conclude that instructional time plays an important role in shaping student pro-social behaviour.

This finding is significant for several reasons: first, in the given context, it is significant because of the sheer number of students affected. In Germany, in school year 2013/14 alone, the reform affects 2,329,990 high school students, about half of the entire student population in secondary education (Federal Statistical Office, 2016b). Second, it is significant because of the important role pro-social behaviour, and in particular volunteering, plays, both for individuals, as described above, and for society at large: the OECD estimates the economic value of volunteering for Germany in 2013 to be around USD 117.6 billion or 3.3\% of real GDP (OECD, 2015), roughly comparable to the UK and the US. Finally, to the extent that students from disadvantaged backgrounds are disproportionally affected, the decrease in volunteering for 
these groups might further increase educational inequalities, and thus inequalities in later life outcomes.

We contribute to two strands of literature: first, we contribute to the economic literature on the external, non-monetary effect of education on civic engagement, which focuses on the effect of years of education on predominantly political interest, information, and participation (Dee, 2004; Dhillon and Peralta, 2002; Milligan et al., 2004 Pelkonen, 2012; Siedler, 2010), as well as reciprocity (Fehr and Gachter, 2000; Kosse et al., 2014) 5 Here, the study most closely related to ours is Gibson (2001): the author uses a sample of twins to hold unobservable family characteristics constant, showing that more years of education are associated with a lower probability of volunteering and supply of volunteer hours. We complement this study by focusing on intensity rather than amount of instruction. ${ }^{6}$ Second, we contribute to the literature on instructional time (Bellei, 2009, Cortes and Goodman, 2014, Cortes et al., 2015, Herrmann and Rockoff, 2012; Taylor, 2014), and in particular, to the stream that exploits the "G8" reform as a source of exogenous variation: since the first data have become available, the reform has been used - due to its features - as a laboratory for empirical research in educational economics. The more sophisticated studies use difference-in-differences approaches that exploit variation in its implementation across federal states and school cohorts; they examine its effects on graduation age, grade repetition, and graduation rates (Huebener and Marcus, 2015), post-secondary

\footnotetext{
${ }^{5}$ See Lochner (2011) and Oreopoulos and Salvanes (2011) for reviews.

${ }^{6}$ Next to this literature in economics stands a large body of literature in political science on the relationship between education and political participation, especially voter turnout. See, for example, Henderson and Chatfield (2011), Hillygus (2005), Persson (2014), and Sondheimer and Green (2010), to name just a few.
} 
educational choices (Meyer et al., 2015), and student performance Andrietti, 2016. Homuth, 2012, Huebener et al., 2016). Here, the studies that are methodologically most closely related to ours are Dahmann and Anger (2014) and Dahmann (2015): we use the same dataset and a similar specification as these authors, who show that the reform affects personality traits, and to some extent, cognitive skills. So far, the potentially negative effects on leisure activities of youth and adolescents have played only a minor role relative to educational outcomes, although this point has sparked considerable controversy amongst students, parents, and educators alike (see, for example, Süddeutsche Zeitung (2010) for a feature), and continues to do so today. The study that is content-wise closest related to ours is Meyer and Thomsen (2015): the authors use self-collected cross-section data on students from the double graduation cohort (which might be subject to implementation effects) in the federal state of Saxony-Anhalt two years after graduation, showing that students in this cohort and state indeed feel more pressured and tend to spend less time on leisure activities such as jobbing or volunteering. More generally, the impact of instructional time on student pro-social behaviour has received little attention so far.

The rest of this paper is organised as follows: Section 2 describes the data used in the empirical analysis, Section 3 the empirical model and identification strategy. The results, including robustness checks, are presented in Section 4. Section 5 discusses them against the background of recent trends in the educational sector, and gives policy implications. 


\section{Data}

\subsection{German Socio-Economic Panel Study}

The German Socio-Economic Panel Study (SOEP) 7 is a representative panel of private households in Germany. It has been conducted annually since 1984, and includes almost 30,000 individuals in more than 11,000 households in its current wave. The SOEP provides rich information on all household members, covering Germans living in the old and new federal states, foreigners, and recent immigrants (Wagner et al., 2007, 2008). Most importantly, it provides information on the volunteering, scholastic involvement, and political interest of youth and adolescents, as well as on their demographic, educational, and parental household characteristics.

During fieldwork, typically, two types of questionnaires are administered: an individual questionnaire is filled out by each household member aged 18 and above; a separate household questionnaire is filled out by the household head. The former covers personal characteristics such as education, leisure activities, and attitudes, the latter household and neighbourhood characteristics that apply to all household members equally. Moreover, since 2000, a separate youth questionnaire including both prospective and retrospective items on childhood and schooling is administered to youth in the year in which they turn 17 . This is when individuals enter the SOEP at the earliest. If they enter at a later point in time, they are administered - in addition to the individual questionnaire - a supplementary biography questionnaire that includes most of the items of the youth questionnaire in order to complement

\footnotetext{
${ }^{7}$ Socio-Economic Panel (SOEP), data for years 1984-2014, version 31, SOEP, 2015, doi: 10.5684/soep.v31
} 
missing information.

The youth questionnaire is our main data source: it includes items on the volunteering, scholastic involvement, and political interest of youth annually from 2006 onwards. To increase sample size, we complement these data with data on adolescents from the individual questionnaire, which includes the same items on volunteering biannually from 2001 and on political interest biannually from 2000 onwards (with few exceptions). The supplementary biography questionnaire complements items on scholastic involvement $8^{8}$ The SOEP also provides readily usable, generated items on educational trajectories of respondents, including the year and federal state in which they started school, the type of school they are currently attending, and in case they have already graduated, the year and federal state in which they have graduated, as well as the degree they have obtained. In case the year or state of school enrolment is missing, we impute it using their date of birth or state of residence, respectively $9^{9}$ If we have multiple observations of the same individual, we only include the observation at the youngest age.

We restrict our sample to the years 2000 to 2014, and to individuals aged 17 to 20

\footnotetext{
${ }^{8}$ In unreported robustness checks, we account for between-survey differences at any point in time by including a dummy variable for the respective survey: the results remain robust, and are available upon request. Moreover, we account for within-survey differences over time by routinely controlling for school cohorts.

${ }^{9}$ When benchmarking the imputed values with the original ones, we find that they match in about $99 \%$ of cases for the state and $66 \%$ of cases for the year of school enrolment. Obviously, for the latter, there is some discretion on side of parents (we account for differences in cut-off dates for school enrolment across states and over time): if we assume that parents have a tendency to redshirt, that is, to strategically postpone school enrolment in order to provide their children with educational advantages due to relative and absolute maturity (Bedard and Dhuey, 2006; Black et al. 2011), their children are correctly allocated to the treatment group. Enrolling in school prematurely, on the contrary, is very rare in Germany.
} 
in order to create a homogeneous age group and avoid confounding effects associated with entrance into tertiary education. We focus only on high school students and graduates, as only those have been affected by the reform. In doing so, we omit students from comprehensive schools: as we cannot clearly identify whether these students are attending or graduated from the academic track, we take a conservative approach and omit them altogether. Moreover, we omit all individuals from federal states where the reform has never been implemented, or during years in which it has been implemented only partially. Finally, we omit all individuals with missing observations on outcomes and covariates. Depending on how many observations on outcomes are available, this gives us a sample of 2,010 students for volunteering, 1,765 for scholastic involvement, and 2,315 for political interest. 10

\subsubsection{Outcomes}

Volunteering. We select volunteering as our main outcome for pro-social behaviour. The indicator is obtained from a single-item five-point Likert scale that asks respondents "How often do you do volunteer work in clubs or social services during free time?". Possible answers include "daily" (about $6 \%$ of respondents), "every week" (16\%), "every month" (12\%), "less often" (30\%), and "never" (36\%). We create a binary indicator that equals one if respondents volunteer at least once a month, that is, if they volunteer daily, weekly, or monthly, and zero else. About $34 \%$ of respondents do so.

Figure A.2 shows the development of this outcome over the observation period.

\footnotetext{
${ }^{10}$ If not stated otherwise, descriptive statistics are given on the sample for volunteering.
} 
The $\mathrm{x}$-axis denotes the interview year, and the $\mathrm{y}$-axis the fitted annual mean, covariate adjusted for observables described in Sub-Section 2.1.2.

\section{Figure A.2 about here}

We can see that, over the past decade, there has been an initial rise in the share of students that volunteer at least once a month, up until the year 2005, whereafter this share started to decline until slightly below its initial value in the year 2014. ${ }^{11}$

As this indicator is framed in such a way as to refer to activities outside school, we select various ways of scholastic involvement as additional outcomes to cover activities inside, in line with a broad definition of pro-social behaviour. The respective indicators are obtained from a battery of binary items that asks respondents "Besides normal classes, there are also other ways to get involved in school. Have you ever - before or right now - been involved in one or more of the following ways?" Possible answers include "student representative" (about 3\% of respondents), "class representative" (41\%), "school magazine" (10\%), "drama or dance group" (20\%), "choir or orchestra" (33\%), "sports group" (28\%), "other voluntary group" (37\%), and "none" (20\%). We a create binary indicator for each activity that equals one if respondents have ever been engaged in it, and zero else.

Political Interest. Apart from items on voting intentions in federal elections, the SOEP does not include specific items on political behaviour, for example, on mem-

\footnotetext{
${ }^{11}$ Figure W.1 in the Web Appendix shows the development of volunteering for students in the lower and intermediate track: compared to those in the upper track, these students tend to volunteer less. The rise in the share that volunteers at least once a month prolongs much longer, up until the year 2009, whereafter it starts to decline.
} 
bership in political parties or participation in youth organisations ${ }^{12}$ However, it regularly asks respondents about their degree of interest in politics more generally. As interest has long been seen as a necessary condition for subsequent behaviour (Fishbein and Ajzen, 1975), we select political interest as outcome to proxy for political behaviour. The indicator is obtained from a single-item four-point Likert scale that asks respondents "Generally speaking, how much are you interested in politics?". Possible answers include "very much" (about 7\% of respondents), "much" (26\%), "not so much" (51\%), and "not at all" $(15 \%)$. We create a binary indicator for each of these categories.

\subsubsection{Covariates}

We routinely control for age and whether a student has graduated in all our regressions. The mean age of students is 17.5 , and only $4 \%$ of them have already graduated. We also routinely control for age squared to account for non-linearities of outcomes with respect to age.

Moreover, in our preferred specification, we control for a rich set of other demographic and parental household characteristics. These include gender (about 53\% of students are female), migration background (about 19\% have a migration background, either direct or indirect), and place of residence (about 13\% live in East Germany and $28 \%$ live in rural areas). When it comes to their parents, about $53 \%$

\footnotetext{
${ }^{12}$ As federal elections (normally) happen only once every four years, the sample size is not large enough to analyse these items. The SOEP also asks respondents whether they lean towards a specific party, and if so, towards which party they lean and to what extent. As there is no a priori reason to believe that an increase in instructional time changes political orientation, we do not analyse these items.
} 
of students have at least one parent with a tertiary degree, $13 \%$ have a parent that is a blue-collar worker, and $65 \%$ have a parent that works full time. Finally, about $19 \%$ of students are risen by a single parent, and about $17 \%$ are the only child. The average number of children in the household is 2.4. See Table W.1 in the Web Appendix for more descriptive statistics.

\section{Empirical Strategy}

To investigate whether raising instructional time can crowd out pro-social behaviour, we exploit the recent educational reform in Germany that reduced the number of school years required to obtain the university entrance qualification as a quasi-natural experiment. Specifically, we set up a difference-in-differences design that exploits variation in the implementation of the reform across federal states and school cohorts: students are allocated to the treatment group if they belong to a school cohort in a federal state which was affected by the reform (or, in other words, if they enrolled in the year in which the reform was implemented or any year thereafter in the respective federal state), and to the control group else. Thus, students in the treatment group are exposed to a higher average weekly instructional time of $12.5 \%$ plus accompanying coursework than those in the control group. For both groups, however, the taught curriculum is the same. From 2,010 students in our sample on volunteering, 762 are in the treatment and 1,248 are in the control group; for scholastic involvement, these are 743 and 1,022 out of 1,765 students, and for political interest 781 and 1,534 out of 2,315 . 


\subsection{Regression Equation}

We employ linear probability models, which are estimated using ordinary least squares with robust standard errors clustered at the federal state level ${ }^{13}$ More specifically, following Dahmann and Anger (2014) and Dahmann (2015), we use the following specification:

$$
\begin{aligned}
y_{i s c,(17-20)=\beta_{0}} & +\beta_{1} \text { Reform }_{s c}+\boldsymbol{\beta}_{2}^{\prime} \mathbf{X}_{\mathbf{i s c},(\mathbf{1 7}-\mathbf{2 0})}+ \\
& +\sum_{s=1}^{16} \gamma_{s} \text { State }_{s}+\sum_{c=1}^{14} \delta_{c} \text { Cohort }_{c}+\epsilon_{i s c,(17-20)}
\end{aligned}
$$

where $y$ is the pro-social behaviour of student $i$ in federal state $s$ and school cohort $c$, measured at age 17 to 20; Reform is a dummy variable that equals one if the student belongs to a school cohort in a federal state which was affected by the reform, and zero else; and $X$ is a vector of controls, including demographic, educational, and parental household characteristics. We routinely include a full set of federal state and school cohort dummy variables. ${ }^{14}$ Our regressor of interest is $\beta_{1}$, which captures the reform effect. It can be interpreted as the average treatment effect on the treated, and is causal if the identifying assumptions described in Sub-Section 3.2 hold.

\footnotetext{
${ }^{13}$ In our preferred specification, less than $1 \%$ of predicted values lie outside the $[0 ; 1]$ interval. Moreover, the results are similar when using a probit model, as shown in Table A.5. Out-of-sample prediction, therefore, seems to be less of an issue. Finally, the results remain the same when using weighted regressions and bootstrapped standard errors. See Table W.4 in the Web Appendix for these results.

${ }^{14} \mathrm{We}$ also routinely include controls for sub-samples, as the SOEP consists of 16 random samples, which partly focus on different population strata.
} 
This difference-in-differences design has two features. First, it is generalised in the sense that treatment can occur at different points in time for different individuals. In fact, at any point in time over the observation period, we compare students who are affected by the reform with those who are not (yet) affected. Thus, towards the beginning of the observation period, the treatment group is relatively small, and as the reform gradually fades in, it increases as more and more observations on affected students become available, and vice versa for the control group. Second, this difference-in-differences design is pseudo in the sense that we only observe each student once. This is due to the fact that individuals enter the SOEP in the year in which they turn 17 at the earliest ${ }^{15}$ In other words, at the point of the first interview, students are near school completion, or even shortly thereafter. As a consequence, we cannot observe their pre-treatment outcomes, which would have had to be recorded prior to enrolment ${ }^{16}$

This difference-in-differences design imposes stronger identifying assumptions than a conventional one. For example, we cannot readily net out unobserved heterogeneity amongst individuals by including individual fixed effects; rather, in case there is unobserved heterogeneity, we have to assume that there is a balance in unobservable characteristics between treatment and control group, and that this balance

\footnotetext{
${ }^{15}$ The SOEP also includes several mother-child questionnaires, which have been administered since 2003. However, these questionniares, which are highly age-specific and cover the age span from birth to 10, are completed by the mother and do not include the items that are relevant for this study. A separate student questionnaire, covering ages 11 and 12, has been administered since 2014 only (and does not include these items either).

${ }^{16}$ Strictly speaking, even if we would observe their pre-treatment outcomes, it is questionable whether we could use them effectively: the kind of pro-social behaviour we are interested in plays a relatively minor role prior to age 12 .
} 
remains constant over time (this is sometime referred to as bias stability) Heckman et al., 2009). In Sub-Section 3.2 we provide evidence that, although our identifying assumptions are stronger, they are likely to hold.

\subsection{Identification}

Our main identifying assumption is that, in the absence of treatment, the prosocial behaviour of students in the treatment group would have followed the same time trend as that of students in the control group. Although this common trend assumption is not formally testable as the counterfactual is not observable, in SubSections 3.2.1 and 3.2.2, we provide evidence that it is likely to hold. ${ }^{17}$

\subsubsection{Balancing on Observables}

The first piece of evidence comes from Table A.1. it shows the means of all covariates, overall and separately for treatment and control group, along with their scale-free normalised differences. Here, covariate imbalance between treatment and control group could indicate a deviation from a common time trend.

\footnotetext{
${ }^{17}$ Implicitly, we also require ignorability and the stable unit treatment value assumption to hold: the former implies that treatment assignment is independent of the outcome, the latter that whether a student is treated or not should not dependent on the outcome of another student. Both are likely to be true: the rise in instructional time for a student does not depend on the amount of volunteering of that student, neither does it depend on the amount of volunteering of another student. Moreover, there should be no variation in treatment intensity between students. Again, this is likely to be true as the reform aimed at reducing the number of school years only while holding everything else constant. For the vast majority of students in the first school cohorts affected, the resulting rise in instructional time was present from the point of enrolment onwards. Only students in the federal states of Saxony-Anhalt and Mecklenburg-West Pomerania had already started school when the reform was implemented. In fact, these students were in grades seven to nine, in which some schools allocated a disproportionally higher share of the overall rise in instructional time, potentially yielding a different treatment intensity for these students. In Sub-Section 4.2 we explore this possibility in more detail.
} 
Table A.1 about here

Imbens and Wooldridge (2009) suggest that a normalised difference above 0.25 indicates covariate imbalance. This is not the case for most of our covariates: only the age is above the threshold, and whether a student has graduated comes close. This is no surprise, though, given that the reform explicitly aimed at reducing the number of school years, thus indirectly reducing the graduation age. In fact, Huebener and Marcus (2015) estimate that the reform decreased the graduation age by about 10 months. Thus, we conclude that the sample is well-balanced on observables, and therefore most likely on unobservables as well. Finally, we routinely control for age, age squared, and whether a student has graduated in all our regressions in order to rule out any age and graduation effects 18

\subsubsection{Graphical Evidence}

Next, we take a closer look at how volunteering, our main variable of interest, evolves over time. Figure A.3 is constructed similarly as Figure A.2. it shows the development of volunteering over the observation period. The x-axis denotes the interview year. Different from Figure A.2, there are now two y-axes: the left yaxis denotes the fitted annual mean, covariate adjusted for observables, whereas the right $\mathrm{y}$-axis denotes the percentage of the treated that have been interviewed. The vertical line marks the interview year before the first observations of the treated

\footnotetext{
${ }^{18}$ Note that covariance imbalance between treatment and control group would not necessarily be a threat to our identification strategy: we control for a rich set of time-varying observables in our preferred specification. Moreover, including federal state and school cohort dummy variables nets out systematic differences in both time-invariant observables and unobservables between federal states and school cohorts, respectively.
} 
become available.

Figure A.3 about here

It is clearly visible that the vertical line marks a structural break, dividing the observation period into two: using local-mean polynomial smoothing, we can see that there is a clear upwards trend in volunteering in the first half of the observation period, whereas in the second, this trend is reversed. Moreover, the trend reversal coincides with an increasing share of the treated amongst the interviewed.

Figure A.4 takes Figure A.3 one step further: it decomposes, in the second half of the observation period, the overall mean into that of the treatment and control group, respectively. It also plots - in addition to that of the overall mean - the polynomial fit of the control group mean ${ }^{19}$

\section{Figure A.4 about here}

We can make three observations. First, when focusing on the control group mean only, it becomes clear that part of the trend reversal in volunteering probably would have come about in the absence of the reform: the polynomial fit of the control group mean tilts downwards irrespective of whether the share of the treated amongst the interviewed increases ${ }^{20}$ Second, the treatment group mean is systematically lower than the control group mean, and as the share of the treated amongst the interviewed increases, the difference between the polynomial fit of the overall and that of the

\footnotetext{
${ }^{19}$ See Figure W.2 in the Web Appendix for a similar illustration of political interest.

${ }^{20}$ This also raises the question to what extent the identified reform effect is driven by time trends. In Sub-Section 4.2 , we explore this possibility in more detail.
} 
control group mean increases as well. This is already suggestive that part of the trend reversal in volunteering is indeed driven by the reform; in our regressions, we are measuring the mean difference between the control group and the treatment group mean in the second half of the observation period. Finally, important for identification, the treatment group mean, when fading in, evolves in parallel to the control group mean, when fading out. This is suggestive of a common trend between treatment and control group.

To illustrate this common trend in more detail, we plot the overall mean for different federal states that implemented the reform quite late during the observation period. Figures A.5 and A.6 are constructed similarly as Figure A.3 they show the overall mean for two groups of states in which the first observations of the treated become available in the same interview year, pooled together, and separately for two large area states in which this is not the case 21

\section{Figures A.5 and A.6 about here}

Again, we can make three observations. First, irrespective of whether we plot the overall mean for groups of states pooled together or separately for single states, there is a common trend between these states before the first observations of the treated become available. Second, the interview year before the first observations of the treated become available marks a structural break. Finally, after this structural break, these states once again exhibit common trend behaviour 22

\footnotetext{
${ }^{21}$ Again, see Figure W.3 in the Web Appendix for a similar illustration of political interest.

${ }^{22}$ The latter point is also suggestive evidence that the stable unit treatment value assumption is likely to hold: common trend behaviour post-treatment implies that treatment intensity is likely to be the same across federal states.
} 
Taken together, the balancing properties of observables and the graphical evidence is clearly supportive of a common trend between treatment and control group. Moreover, in case there is unobserved heterogeneity, there seems to be a balance in unobservable characteristics between them that remains constant over time.

\section{Results}

\subsection{Baseline Results}

We now turn to our baseline results in Table A.2. column (1) includes only the reform dummy variable, our regressor of interest; columns (2) and (3) then successively add age, age squared, and a graduation dummy variable in order to account for age and graduation effects. Finally, column (4) includes all of the above, along with a rich set of other demographic and parental household characteristics; it is our preferred specification, and the regression equivalent to Figure A.3.

\subsubsection{Volunteering}

Table A.2 shows that the reform has a negative and sizeable effect on volunteering across the board, which is significant at the $1 \%$ level: in our preferred specification, it decreases the likelihood to volunteer at least once a month by about six percentage points. The size of this effect is also economically significant: given that almost 34 percent of all students in the sample report to volunteer at least monthly, it amounts to a decrease of about 18 percent in this share. In other words, the reform led almost every fifth student to change her behaviour from volunteering at least monthly to volunteering less often or not at all. The fact that the sign, size, and significance level 
is similar across all models reinforces the notion of a quasi-natural experiment ${ }^{23}$

\section{Table A.2 about here}

The remainder of the coefficients behave as expected: age has a positive and age squared a negative effect on volunteering, suggesting that there is a concave relationship between volunteering and age. None of these coefficients turns out significant, though, which also suggests that restricting the sample to students aged 17 to 20 in order to achieve a homogeneous age group and avoid age effects has worked. Related, having graduated has a positive but insignificant effect on volunteering; however, only a small share (4\%) of students in the sample has already graduated. In fact, the mean age of students in the final sample is 17.5, which is well below the mean age after graduation of 19.7 ${ }^{24}$ Confounding graduation effects therefore seem to be less of an issue.25

As our outcome is a binary indicator constructed from a categorical variable, it would be interesting to see how the overall frequency distribution of volunteering changes due to the reform. Figure A.7 illustrates this: it compares the means of the different frequencies of volunteering before and after the reform.

$$
\text { Figure A.7 about here }
$$

\footnotetext{
${ }^{23}$ This is also suggestive evidence that ignorability is likely to hold, even unconditionally: the fact that our estimates vary so little depending on covariates implies that treatment is likely to be exogenous.

${ }^{24}$ The mean age at graduation is likely to be lower: most interviews are carried out between January and June, and students typically graduate in June. Thus, there may be quite some lag between when students graduate and when we observe them after graduation.

${ }^{25}$ See Table W.2 in the Web Appendix for the full set of controls.
} 
We can make three observations. First, the reform affects the entire frequency distribution of volunteering, as all categories are affected, although to different degrees. Second, the driving force behind the decrease in the share of students that volunteer at least once a month are students that volunteer weekly, followed by those that volunteer monthly: the share of the former drops by about $27 \%$, the share of the latter by about $10 \%$. On the contrary, the share of students that report the highest frequency of volunteering sees almost no reduction (less than 4\%). This, however, is only a small fraction: about $6 \%$ report to volunteer daily, as opposed to about $16 \%$ and $12 \%$ reporting to volunteer weekly and monthly, respectively. Second, these reductions are met with almost equal rises by approximately $10 \%$ in both the share of students that volunteer less often and the share of students that volunteer never; the difference between these flows is significant. This implies that the reform affected both the intensive and the extensive margin of volunteering: while some students cut back on their activities, others gave them up completely, which is broadly in line with the results obtained for the double graduation cohort in the federal state of Saxony-Anhalt by Meyer and Thomsen (2015). At the same time, this might point towards potential effect heterogeneities, and indeed, although there is little evidence that the effects vary much by student demographics and achievement, we find that, in line with findings from other OECD countries (OECD, 2015), students with lower educated parents are up to three times more likely to cut back on their activities (results available upon request).

The question arises whether there is a similar crowding out of scholastic involvement as for volunteering. Alternatively, one could ask whether the crowding out of 
volunteering is matched by an increase in scholastic involvement. In other words, is there a substitution of activities outside school with activities inside? Table A.3 shows that neither is the case: it takes our preferred specification, column (4) in Table A.2, and uses the likelihood of various ways of scholastic involvement as outcomes. Clearly, the reform has no significant effect on any of them, and neither is there a clear pattern in terms of sign. To get a sense of whether the reform affects the extensive margin of scholastic involvement, we also tested an alternative outcome: a binary indicator that equals one if respondents have ever been engaged in any of the activities in columns (a) to (g), and zero else. Again, the reform has no significant effect on this alternative outcome (not shown) ${ }^{26}$ A potential caveat of this analysis is that we have slightly less observations for scholastic involvement than for volunteering: the sample size decreases from 2,010 to 1,765 students. This decrease, however, is mostly driven by students in the control group: 743 are now in the treatment and 1,022 are in the control group.

\section{Table $\AA .3$ about here}

\subsubsection{Political Interest}

Finally, we ask how the reform affects political interest, which we take as a proxy for political behaviour. Table A.4 sheds light on this question. Once again, we take our preferred specification, column (4) in Table A.2, and use the likelihood of being interested in politics with a particular strength, including strongly, fairly, weakly, or

\footnotetext{
${ }^{26}$ In another specification, we excluded the activities in columns (a) and (b). Arguably, these activities should react inelastically to changes in instructional time: by German school law, there has to be a student and a class representative. The result, however, remains the same.
} 
not at all, as outcomes. We also combine the first two categories to form a new one, namely being moderately interested in politics. ${ }^{27}$

\section{Table A.4 about here}

Interestingly, we find that the reform has a differential impact on political interest: it has a significantly positive effect on being weakly interested at the $5 \%$ level. At the same time, however, it has a significantly negative effect on not being interested at all as well as on being moderately interested at the $10 \%$ level ${ }^{28}$ In other words, there is a depolarisation at both ends of the spectrum: the reform decreases the share of students that report to be moderately, that is, at least fairly, interested in politics by about 11 percentage points while at the same time decreasing the share that report to be not interested at all by about five percentage points. Taken together, this equals the incremental 16 percentage points of those being weakly interested. These migration flows are very strong: every third student switches from the higher category to the lower, and vice versa ${ }^{29}$ We find no effect heterogeneities with respect to student student socio-demographics and achievement.

A potential explanation for this differential impact on political interest is that the reform crowds out political interest on one side of the spectrum, namely for those

\footnotetext{
${ }^{27}$ In this analysis, we have slightly more observations: the sample size increases from 2,010 to $2,315,781$ of which are now in the treatment and 1,534 are in the control group.

${ }^{28}$ Although these effects are significant at the $10 \%$ level only, we still interpret them as important, given that our sample size is relatively small. See Table W.3 in the Web Appendix for the results on being moderately interested in politics.

${ }^{29}$ In unreported robustness checks, we include dummy variables for state, federal, and European elections, either individually or jointly: the results remain robust, and if anything, the effect for being moderately interested in politics becomes significant at the $5 \%$ level. The results are available upon request.
} 
already interested in politics, while at the same time encouraging others on the other side to become politically active, especially those who have not been so previously, for example, by joining a protest group or party that opposes the reform. In fact,

the reform has sparked considerable controversy amongst students, parents, and educators alike (some in anticipation of the adverse effects presented in this study), and continues to do so today. This has led some federal states to announce its revocation, and others like the federal state of Rhineland-Palatine not to implement it in the first place.

\subsection{Robustness Checks}

In the following, we conduct a number of robustness checks to confirm the robustness of our baseline results. Specifically, we test whether they remain robust to a different model specification, time trends, and seasonal variation; selection and implementation; and potentially confounding other reforms that are implemented during the observation period. We also conduct a series of placebo tests. All robustness checks build on our preferred specification, column (4) in Table A.2. For the sake of brevity, we focus on volunteering, our main variable of interest.

\subsubsection{Model Specification, Time Trends, and Seasonal Variation}

First, we turn to a different model specification. In column (1) of Table A.5, we use a probit instead of a linear model. As can be seen, the reform still has a negative effect on volunteering, which is significant at the $1 \%$ level. The size of the coefficient, however, is slightly larger.

Table A.5 about here 
Figure A.4 suggests that some of the decline in volunteering during the observation period probably would have come about in the absence of the reform, which raises the question to what extent the identified reform effect is driven by time trends. To be clear, this is not a threat to our identification strategy as long as time trends do not affect treatment and control group differentially, and time trends are not correlated with the outcome. To explore this possibility nevertheless, in columns (2) and (3) of Table A.5, we include a linear and quadratic time trend, respectively. Then, in column (4), we include both of them at the same time. As can be seen, the reform still has a negative effect on volunteering, which is significant at the $1 \%$ level, across all models, and the size of the coefficients is very similar. We go even one step further: in column (5), we include both state-specific linear and quadratic time trends, counting up the years for each state individually, and in column (6), we include both treatment-specific linear and quadratic time trends, counting up the years for each state individually starting from the interview year in which the first observations of the treated amongst the interviewed become available. Arguably, both specifications are very restrictive in the sense that they take out much variation in the data, which is in part reflected by lower significance levels. The point estimates remain, nevertheless, quite robust.

Finally, we turn to seasonal variation. Again, this is not a threat to our identification strategy as long as treatment and control group are not systematically interviewed at different dates, and interview dates are not correlated with the outcome. To explore this possibility nevertheless, in columns (7) and (8) of Table A.5. we include quarterly and monthly dummy variables, respectively. As expected, the 
sign, size, and significance level of the reform effect in both models is very similar to that in our preferred specification 30

\subsubsection{Selection and Implementation}

Next, we turn to selection, which may come in two flavours: within-sample and out-of-sample selection. First, students may self-select from the treatment into the control group within the sample, for example, by moving from one federal state to another in order to avoid the reform ${ }^{31}$ Alternatively, students may self-select out of the sample altogether, for example, by dropping out of high school. To be clear, this is not a threat to our identification strategy as long as self-selection is not correlated with the outcome. Assuming that students who move or drop out are those who are most adversely affected by the reform, our estimates are downward biased and can be interpreted as a lower bound.

We believe that within-sample selection is unlikely to be an issue: moving from one federal state to another is associated with high monetary and non-monetary costs for both students and parents. Besides, geographic mobility in Germany is

\footnotetext{
${ }^{30}$ One might argue that, at the time of interview, students in the treatment group are relatively closer to their high school finals than those in the control group, which might, in turn, partially or even fully account for the identified reform effect. To rule out this non-random measurement error, we follow the approach by Dahmann and Anger (2014), restricting our sample to students aged 17 and interacting our main effect with monthly dummy variables. We do not find a clear pattern in terms of sign, size, and significance level for these interactions; the point estimate of the main effect remains robust, but its significance is greatly reduced, most likely due to loss of observations (about a quarter of our sample). We take this as evidence that non-random measurement error due to time of interview is, if anything, a minor issue.

${ }^{31}$ Implicitly, we assume that students self-select from the treatment into the control group, as they have a preference to avoid the reform. To be more precise, it is unlikely that students themselves self-select; rather, it is their parents who - probably after joint decision-making with their children - decide on taking this action. For simplicitly, we refer to students throughout.
} 
traditionally low: in a given year, only about $6 \%$ of respondents in the SOEP move. This is even more so the case in a selective sample like ours, comprising families with children that attend high school: in a given year, only about $3 \%$ of them move. Nevertheless, in column (1) of Table A.6, we evaluate how movers affect our estimates: here, we exclude all students who move during the observation period. As it turns out, this does not change our estimates much: the reform still has a negative effect on volunteering, which is significant at the $1 \%$ level; the size of the effect is somewhat reduced ${ }^{32}$ A more serious problem arises, however, for students living close to a state border: rather than move to avoid the reform, they may transfer to a school in a neighbouring state that has not yet implemented it, and commute. In column (2) of Table A.6, we exclude all students who live within a $10 \mathrm{~km}$ radius to a state border (about 27\%) ${ }^{33}$ As it turns out, the size of the effect becomes larger, presumably since some of these students are allocated to the treatment group although, in fact, they should be allocated to the control group 34

\section{Table A.6 about here}

Rather than geographically sorting between schools, students may also sort within them, for example, by skipping a grade in order to avoid the reform. Unfortunately,

\footnotetext{
${ }^{32}$ In column (a) of Table W.5 in the Web Appendix, we regress the probability of moving on the reform: the effect is small and insignificant. We take this as evidence that the reform has no effect on moving behaviour per se.

${ }^{33}$ Similar results are obtained when using a 20 or a $30 \mathrm{~km}$ radius.

${ }^{34}$ Related, a staggered self-selection of federal states is also thinkable: first, they decide on whether to implement the reform or not; then, they decide on when to implement it. Again, as long as selfselection is not correlated with the outcome, this does not threaten our identification strategy. Moreover, Dahmann and Anger (2014) convincingly show that federal states which implement the reform early do not systematically differ from those that do so late regarding their proportion of high school students, governing party, next election date, and GDP per capita.
} 
we do not have information on whether a student skipped a grade. We argue, however, that sorting within schools is more of a theoretical problem for three reasons: first, in general, skipping a grade is not entirely discretionary to students, and requires considerable effort in terms of previous academic achievement. Second, those students that are allowed to skip a grade are presumably those that are the least affected by the reform, and thus have the lowest incentive to avoid it. Finally, skipping a grade leads students to graduate in the same cohort as their former peers, which - in terms of time to graduation - has no advantage. Moreover, as we argue below, this double cohort has certain features that render grade-skipping to avoid the reform an unattractive strategy. Related, students may also sort within schools by repeating a grade. Although this is not a feasible strategy to avoid the reform, it could nevertheless affect our estimates, as students could switch from the control to the treatment group. Assuming that students who must repeat a grade under the old regime are likely to struggle even more under the new one, omitting them would bias our estimates downwards. Again, this issue applies only to a small subset of students, namely those that are in the last pre-treatment cohorts preceding the first treatment ones. Nevertheless, in column (3) of Table A.6, we dig deeper into this issue: here, we exclude all students who repeat a grade (about 7\%). We find that the reform still has a negative effect on volunteering, which is significant at the $1 \%$ level. As expected, the size of the effect is somewhat reduced 35

Finally, we turn to out-of-sample selection: clearly, if dropping out of high school

\footnotetext{
${ }^{35}$ As with moving, in column (b) of Table W.5 in the Web Appendix, we regress the probability of repeating a grade on the reform: the effect is small and insignificant.
} 
were a deliberate strategy to avoid the reform, it would be the one with the highest opportunity costs, as students would effectively forego their university entrance certificate. In column (4) of Table A.6, we evaluate how drop-outs affect our estimates: here, we exclude all students who drop out of high school (about 8\%). As it turns out, the sign, size, and significance level of the effect is very similar to that in our preferred specification $[36$

Although the reform has been swiftly integrated into the German secondary education landscape, there may have been various implementation effects - confounding one-off effects arising from the implementation of the reform into regular school business. This is particularly true for students in double, first treatment, and last pre-treatment cohorts, across all federal states ${ }^{37}$ Moreover, in the federal states of Saxony-Anhalt and Mecklenburg-West Pomerania, students in the first treatment cohorts had already started school when the reform was implemented. For example, for students in the double cohort, such implementation effects may be due to increased competition for educational and post-educational resources; for students in the first treatment cohort, they may be due to inexperience of teachers in delivering material at a faster pace, or insecurity on side of students; and for students in the last pretreatment cohort, they may be due to increased motivation not to repeat a grade, and be affected by the reform. On the other hand, teachers may treat students in

\footnotetext{
${ }^{36}$ Once again, in column (c) of Table W.5 in the Web Appendix, we regress the probability of dropping out on the reform: the effect is small and insignificant. We take this as evidence that the reform has no effect on dropping out. This is in line with Huebener and Marcus (2015) who find that the reform does not affect drop-out rates.

${ }^{37}$ We define the first treatment cohorts as the cohorts succeeding the double cohorts in order to avoid mixing up implementation effects.
} 
these cohorts in a more easy way. Although it is unlikely that such implementation effects are the driving force behind the aggregate effect, they can still affect our estimates.

In columns (5) to (8) of Table A.6, we explore this possibility in more detail: here, we include state-specific controls individually for students in double, first treatment, and last pre-treatment cohorts, as well as for students in the first treatment cohorts in the federal states of Saxony-Anhalt and Mecklenburg-West Pomerania. If anything, we find that controlling for cohorts that might suffer from implementation effects slightly increases the aggregate effect in our preferred specification. Confounding implementation effects, therefore, seem to be less of an issue ${ }^{38}$

\subsubsection{Others Reforms}

Over the past two decades, there have been various other reforms in the German secondary education landscape, some of which fall into the observation period, and could potentially be confounding ${ }^{39}$ For example, having long been standard in the majority of states, the remainder has only recently moved towards state-wide harmonised high school finals by introducing central exit examinations. Others, trying to open up the traditionally less permeable and rigid German education system, introduced changes to the grade at which tracking takes place, or reduced tracking altogether by combining the lower and intermediate tracks into a single one. Yet others have introduced changes to the choice of subjects available to high school seniors.

\footnotetext{
${ }^{38}$ In column (3) of Table W.4 in the Web Appendix, we go even one step further and control for all cohorts that might suffer from implementation effects at the same time: the result remains the same.

${ }^{39}$ See Huebener and Marcus (2015) for a detailed overview of these reforms.
} 
Probably the biggest change in recent decades, however, has been the abolishment of mandatory military or civil service right after finishing secondary education: in 2011, it was replaced with the (non-mandatory) Federal Volunteer Service.

To be clear, it is unlikely that any of these reforms systematically biases our estimates for two reasons: first, it would have to be correlated with the outcome. More importantly, however, it would have to affect treatment and control group differentially. This would be the case if reforms were correlated, for example, if reducing the number of years required to obtain a high school degree went hand in hand with restricting the subject choice available to high school seniors. Alternatively, one could argue that states which are more prone to reform may be the first to reduce the number of high school years, and may also be inclined to introduce other reforms shortly after, or the other way around.

To rule out this possibility, in columns (1) to (5) of Table A.7, we include statetime-specific controls for these potentially confounding other reforms. As expected, the sign, size, and significance level of the coefficients is very similar to that in our preferred specification. Likewise, excluding students who have already graduated, and who might thus be participating in the Federal Volunteer Service, leaves results unchanged (results available upon request). Confounding other reforms, therefore, seem to be less of an issue 40

\section{Table A.7 about here}

\footnotetext{
${ }^{40}$ In column (4) of Table W.4 in the Web Appendix, we go even one step further and control for all potentially confounding reforms at the same time: the result remains the same.
} 


\subsubsection{Placebo Tests}

Finally, as a last exercise, we conduct placebo tests: in columns (1) and (2) of Table A.8, we lag the first treatment cohort by one and two, respectively; in columns (3) and (4), we randomly allocate treatment status to school cohorts and federal states, respectively, keeping the other constant. Finally, in column (5), we completely perturb both school cohorts and federal states, and then randomly allocate treatment status. As can be seen, none of the coefficients is significant at any conventional level. For the first two columns, we can see that the coefficients are negative, pointing towards the overall trend reversal in volunteering we see during the observation period; the fact that the coefficient of the second column is slightly larger than that of the first one suggests that there are no ex-ante behavioural changes due to anticipation effects (Ashenfelter's dip). Note that in both of these columns, we lose observations that fall out of the observation period window. For the last three columns, we cannot observe a clear pattern of coefficients.

\section{Table A.8 about here}

\section{Discussion and Policy Implications}

In sum, we find robust empirical evidence that raising instructional time has the potential to significantly affect student leisure activities and behaviours, and in particular, to significantly crowd out student pro-social behaviour, a behaviour that is linked to various positive outcomes - both at the societal and individual level and that parents, educators, and policy-makers alike would otherwise consider worth promoting. In the given context, an about 13 percent rise in weekly instructional 
hours had a negative and sizeable effect on volunteering, decreasing the share of students that volunteer at least once a month by about 18 percent. In other words, it led almost every fifth student to change her behaviour from volunteering at least monthly to volunteering less often or not at all. Students that volunteer on a regular basis are most adversely affected, and there is evidence that students with lower educated parents are up to three times more likely to disengage. While half of students cut back on their activities, the other half give them up completely. We find no similar crowding out of involvement in activities within school, but no substitution either. Finally, there is some evidence that raising instructional time also has the potential to affect political interest, which we take as a proxy for political behaviour.

Why are these findings important? First of all, in the given context, they are important because of the large number of students affected. In Germany, in school year 2013/14 alone, of 2,329,990 high school students in total (Federal Statistical Office, 2016b), about 786,000 volunteer at least monthly. We estimate that the rise in instructional time decreases this share by about 134,000: 75,000 cut back on their activities, and 59,000 give them up completely. It is difficult to measure the economic value of volunteering for society: there exist various definitions of volunteering, and at least as many ways to measure it, for example through national accounts, labour force surveys, or social or time use surveys. It is clear, however, that this value is substantial 41 Through time use surveys, the OECD estimates the economic value of volunteering for Germany in 2013 to be around USD 117.6 billion or 3.3\% of real

\footnotetext{
${ }^{41}$ See The Economist $(2014)$ for a recent feature.
} 
GDP (OECD, 2015) ${ }^{42}$ We can calculate back-of-the-envelope that losing between 59,000 and 134,000 volunteers is equal to losing volunteer work worth between USD 85.9 million and USD 195 million ${ }^{43}$ These figures are likely to be a lower bound for two reasons: first, volunteering in the general population is less prevalent than in the population under scrutiny 44 Second, to the extent that volunteering during youth and adolescence contributes to habit formation (Hart et al., 2007) and has positive peer effects (Wilson and Musick, 1997), impacts may be permanent rather than temporary. Besides these negative effects for society per se, the decrease in volunteer work can also have negative micro implications: a growing body of evidence documents the importance of volunteering for individual labour market outcomes. For example, in a recent correspondence testing study, Baert and Vujić (2016) show that job seekers who indicate volunteering on their resumes receive one third more interview invitations, and that this volunteering premium is higher for women. A leading professional social network, LinkedIn (2016), using data on members, estimates that one in five managers hire someone because of their volunteer experience. Sauer (2015), using a structural model and longitudinal data for the US, estimates that an extra year of pro-social engagement increases wage offers in future full-time (part-time) work by $2.6 \%$ (8.5\%) for women aged 25 to 55 , in line with Freeman

\footnotetext{
${ }^{42}$ This figure is roughly comparable to the UK $(2.5 \%)$ and to the US $(3.7 \%)$.

${ }^{43}$ There were 80.8 million people living in Germany in 2013 (Federal Statistical Office, 2016a). Thus, assuming the distribution of activities in the general population is similar to that in the population under scrutiny, the loss in volunteer work can be calculated as $(117,600,000,000 \times$ $59,000) / 80,800,000$ and $(117,600,000,000 \times 134,000) / 80,800,000$, respectively, for the 59,000 students giving up and for the 134,000 students cutting back and giving up their activities.

${ }^{44}$ In the general population, only about $23 \%$ of individuals report to volunteer at least once a month, according to the OECD. In the SOEP, this share is even lower: 20\%. Again, both figures are roughly comparable to the UK (18\%) and to the US (30\%).
} 
(1997) who estimates that volunteering raises paid work hours by between $3 \%$ and $7 \%$. There is evidence that being engaged from an early age on enhances psychological development by raising self-esteem and self-confidence and by discouraging risky behaviours (Hart et al., 2007; Wilson and Musick, 2012). The physical and mental health benefits of volunteering (Wilson and Musick, 2012), as well as its subjective well-being returns are well established (Binder and Freytag, 2013; Meier and Stutzer, 2008). Finally, to the extent that students from disadvantaged backgrounds are disproportionally affected, the role that volunteering can play in the production process of skills, for example, through generating early life skills that complement other skills later on (Cunha and Heckman, 2007, Fuchs, 2016), or in the selection process for further education, as is for example the case in the German scholarship system or for admissions to US colleges, the decrease in volunteering for these groups might further increase educational inequalities, and thus inequalities in later life outcomes ${ }_{45}^{45}$

To be clear, we are not advocating that raising instructional time is a bad idea per se: it is often found to have positive impacts on student learning and performance, especially when the additional time is used effectively, and there surely is an optimal amount of weekly instructional hours that balances student learning with student leisure activities and behaviours. For a more complete cost-benefit account of raising instructional time, however, its impacts on student leisure activities and behaviours, in particular on beneficial behaviours such as volunteering, should be taken into account. Education policy could consider, for example, providing volunteering

\footnotetext{
${ }^{45}$ See The Behavioural Insights Team $(2016)$ for a recent impact evaluation of programmes that promote social action: it shows that such programmes can nurture skills such as empathy or grit that are critical for educational success.
} 
opportunities such as high school community service within schools, or encouraging it through the curriculum, for example, by introducing volunteering days.

There are many limitations to this study, which is only a cautious exploration into the relationship between instructional time and student pro-social behaviour. The most obvious is that we cannot say anything about how persistent the identified effects are. The fact that controlling for graduation status reduces the size of the coefficient estimates only slightly suggests that they are rather permanent, though, in line with findings on habit formation (Hart et al., 2007). Once more data become available, it would be interesting to test this formally. External validity is another issue. The fact that the UK and the US exhibit similar profiles regarding instructional time and volunteering demographics than Germany (Bureau of Labor Statistics, 2015: OECD, 2015) might point towards the fact that findings are rather transferable. 


\section{Acknowledgements}

We would like to thank Claudia Senik, Nicolas Ziebarth, Heike Solga, Sarah Dahmann, Mathias Huebener, Christopher Wratil, and especially Jürgen Schupp for valuable comments and suggestions. We are also thankful to Jan Goebel for continuous support with the SOEP. Falk Voit provided excellent research assistance. All remaining shortcomings and errors are our own.

\section{Project Funding}

German Ministry for Education and Science

FKZ: NIMOERT2/Kassenzeichen: 8103036999784/\#30857

Projekt: "Nicht-monetäre Eträge von Bildung in den Bereichen Gesundheit, nichtkognitive Fähigkeiten sowie gesellschaftliche und politische Partizipation" 
Andrietti, V. (2016). The Causal Effects of an Intensified Curriculum on Cognitive Skills: Evidence from a Natural Experiment. Universidad Carlos III de Madrid Working Paper, Economic Series 16-06.

Baert, S. and S. Vujić (2016). Does it Pay to Care? Pro-Social Engagement and Employment Opportunities. IZA Discussion Paper 9649.

Batson, C. D. and A. A. Powell (2003). Altruism and Prosocial Behavior. In I. B. Weiner (Ed.), Handbook of Psychology, Volume 5. London: Wiley.

Bedard, K. and E. Dhuey (2006). The Persistence of Early Childhood Maturity: International Evidence of Long-Run Age Effects. The Quarterly Journal of Economics 121(4), 1437-1472.

Bellei, C. (2009). Does Lengthening the School Day Increase Students' Academic Achievement? Results from a Natural Experiment in Chile. Economics of Education Review 28(5), 629-640.

Binder, M. and A. Freytag (2013). Volunteering, Subjective Well-Being, and Public Policy. Journal of Economic Psychology 34, 97-119.

Black, S. E., P. J. Devereux, and K. G. Salvanes (2011). Too Young to Leave the Nest? The Effects of School Starting Age. The Review of Economics and Statistics 93(2), 455-467.

Bureau of Labor Statistics (2015). Volunteering in the United States, 2015. http: //www.bls.gov/news.release/volun.nr0.htm. 
Cattaneo, A., C. Oggenfuss, and S. C. Wolter (2016). The More, The Better? The Impact of Instructional Time on Student Performance. CESifo Working Paper 5813 .

Cortes, K. E. and J. S. Goodman (2014). Ability-Tracking, Instructional Time, and Better Pedagogy: The Effect of Double-Dose Algebra on Student Achievement. American Economic Review 104(5), 400-405.

Cortes, K. E., J. S. Goodman, and T. Nomi (2015). Intensive Math Instruction and Educational Attainment: Long-Run Impacts of Double-Dose Algebra. Journal of Human Resources 50(1), 108-158.

Cunha, F. and J. Heckman (2007). The Technology of Skill Formation. American Economic Review 97(2), 31-47.

Dahmann, S. (2015). How Does Education Improve Cognitive Skills? Instructional Time Versus Timing of Instruction. SOEPpapers on Multidisciplinary Panel Data Research 769.

Dahmann, S. and S. Anger (2014). The Impact of Education on Personality: Evidence from a German High School Reform. IZA Discussion Paper 8139.

Dee, T. S. (2004). Are There Civic Returns to Education? Journal of Public Economics 88(9-10), 1697-1720.

Dhillon, A. and S. Peralta (2002). Economic Theories of Voter Turnout. The Economic Journal 112(480), F332-F352. 
Eisenberg, N., T. L. Spinrad, and A. S. Morris (2013). Prosocial Development. In P. D. Zelazo (Ed.), Oxford Handbook of Developmental Psychology, Volume 2. Oxford: Oxford University Press.

Federal Agency for Cartography and Geodesy (2016). Administrative Areas 1:2,500,000. http://www.geodatenzentrum.de.

Federal Statistical Office (2016a). Genesis Online, Table 12411-0001 - Population: Germany, Effective Date December 31, 2013. http://www.destatis.de.

Federal Statistical Office (2016b). Genesis Online, Table 21111-0003 - Students: Federal States, School Year 2013/14, Gender, School Type. http://www.destatis. de.

Fehr, E. and S. Gachter (2000). Fairness and Retaliation: The Economics of Reciprocity. Journal of Economic Perspectives 14(3), 159-181.

Fishbein, M. and I. Ajzen (1975). Belief, Attitude, Intention, and Behavior: An Introduction to Theory and Research. Addison-Wesley.

Freeman, R. B. (1997). Working for Nothing: The Supply of Volunteer Labor. Journal of Labor Economics 15(1), S140-S166.

Fuchs, B. (2016). The Effect of Teenage Employment on Character Skills, Expectations, and Occupational Choice Strategies. Hohenheim Discussion Papers in Business, Economics, and Social Sciences 14-2016.

Gibson, J. (2001). Unobservable Family Effects and the Apparent External Benefits of Education. Economics of Education Review 20(3), 225-233. 
Hart, D., T. M. Donnelly, J. Youniss, and R. Atkins (2007). High School Community Service as a Predictor of Adult Voting and Volunteering. American Educational Research Journal 44(1), 197-219.

Heckman, J. J., R. J. LaLonde, and J. A. Smith (2009). The Economics and Econometrics of Active Labor Market Programs. Handbook of Labor Economics 3.

Henderson, J. and S. Chatfield (2011). Who Matches? Propensity Scores and Bias in the Causal Effects of Education on Participation. The Journal of Politics 73(3), 646-658.

Herrmann, M. A. and J. E. Rockoff (2012). Worker Absence and Productivity: Evidence from Teaching. Journal of Labor Economics 30(4), 749-782.

Hillygus, D. S. (2005). The Missing Link: Exploring the Relationship Between Higher Education and Political Behavior. Political Behavior 27(1), 25-47.

Homuth, C. (2012). Der Einfluss des achtjaehrigen Gymnasiums auf den Kompetenzerwerb. Bamberg Graduate School of Social Sciences.

Huebener, M., S. Kuger, and J. Marcus (2016). Increased Instruction Hours and the Widening Gap in Student Performance. DIW Berlin Discussion Papers 1561.

Huebener, M. and J. Marcus (2015). Moving up a Gear: The Impact of Compressing Instructional Time Into Fewer Years of Schooling. DIW Berlin Discussion Papers 1450 .

Imbens, G. W. and J. M. Wooldridge (2009). Recent Developments in the Econometrics of Program Evaluation. Journal of Economic Literature 47(1), 5-86. 
Kosse, F., T. Deckers, H. Schildberg-Hörisch, and A. Falk (2014). Formation of Human Pro-Sociality: Causal Evidence on the Role of Social Environment. mimo.

Lavy, V. (2015). Do Differences in Schools' Instruction Time Explain International Achievement Gaps? Evidence from Developed and Developing Countries. The Economic Journal 125(588), F397-F424.

LinkedIn (2016). LinkedIn. http://www.linkedin.com.

Lochner, L. (2011). Non-Production Benefits of Education: Crime, Health, and Good Citizenship. In E. Hanushek, S. Machin, and L. Woessmann (Eds.), Handbook of the Economics of Education, Volume 4. Amsterdam: Elsevier.

Meier, S. and A. Stutzer (2008). Is Volunteering Rewarding in Itself? Economica $75(297), 39-59$.

Meyer, T. and S. L. Thomsen (2015). Schneller fertig, aber weniger Freizeit? Eine Evaluation der Wirkungen der verkürzten Gymnasialzeit auf die außerschulischen Aktivitäten der Schülerinnen und Schüler. Schmollers Jahrbuch 135, 249-278.

Meyer, T., S. L. Thomsen, and H. Schneider (2015). New Evidence on the Effects of the Shortened School Duration in the German States: An Evaluation of PostSecondary Education Decisions. IZA Discussion Paper $950 \%$.

Milligan, K., E. Moretti, and P. Oreopoulos (2004). Does Education Improve Citizenship? Evidence from the United States and the United Kingdom. Journal of Public Economics 88(9-10), 1667-1695. 
OECD (2014). Education at a Glance 2014. OECD Publishing.

OECD (2015). How's Life? 2015: Measuring Well-Being. OECD Publishing.

OECD (2016). Student Learning Time: A Literature Review. OECD Education Working Paper (127).

Oreopoulos, P. and K. G. Salvanes (2011). Priceless: The Non-Pecuniary Benefits of Schooling. Journal of Economic Perspectives 25(1), 159-184.

Patall, E. A., H. Cooper, and A. B. Allen (2010). Extending the School Day or School Year: A Systematic Review of Research (1985-2009). Review of Educational Research 80(3), 401-436.

Pelkonen, P. (2012). Length of Compulsory Education and Voter Turnout: Evidence from a Staggered Reform. Public Choice 150(1), 51-75.

Persson, M. (2014). Testing the Relationship Between Education and Political Participation Using the 1970 British Cohort Study. Political Behavior 36(4), 877-897.

Putnam, R. D. (2000). Bowling Alone: The Collapse and Revival of American Community. "New York": Simon and Schuster.

Rivkin, S. G. and J. C. Schiman (2015). Instruction Time, Classroom Quality, and Academic Achievement. The Economic Journal 125(588), F425-F448.

Sauer, R. M. (2015). Does it Pay for Women to Volunteer? International Economic Review 56(2), 537-564. 
Süddeutsche Zeitung (2010). Unterricht, der krank macht. http://www. sueddeutsche.de/karriere/ stress-durch-ganztagsschulen-unterricht-der-krank-macht-1.942372.

Siedler, T. (2010). Schooling and Citizenship in a Young Democracy: Evidence from Postwar Germany. Scandinavian Journal of Economics 112(2), 315-338.

Sondheimer, R. M. and D. P. Green (2010). Using Experiments to Estimate the Effects of Education on Voter Turnout. American Journal of Political Science 54(1), $174-189$.

Standing Conference of the Ministers of Education and Cultural Affairs (2016). High School (German only). https://www.kmk.org/ themen/allgemeinbildende-schulen/bildungswege-und-abschluesse/ sekundarstufe-ii-gymnasiale-oberstufe-und-abitur.html.

Taylor, E. (2014). Spending More of the School Day in Math Class: Evidence from a Regression Discontinuity in Middle School. Journal of Public Economics 117, $162-181$.

The Behavioural Insights Team (2016). Evaluating Youth Social Action: Does Participating in Social Action Boost the Skills Young People Need to Succeed in Adult Life? Final Report.

The Economist (2014). The Economics of Volunteering: Hiding in Plain Sight. http://www.economist.com/blogs/freeexchange/2014/09/ economics-volunteering. 
Wagner, G. G., J. R. Frick, and J. Schupp (2007). The German Socio-Economic Panel Study (SOEP) - Scope, Evolution, and Enhancements. Schmollers Jahrbuch 127(1), 139-169.

Wagner, G. G., J. Goebel, P. Krause, R. Pischner, and I. Sieber (2008). Das SozioOekonomische Panel (SOEP): Multidisziplinaeres Haushaltspanel und Kohortenstudie fuer Deutschland - Eine Einfuehrung (fuer neue Datennutzer) mit einem Ausblick (fuer erfahrene Anwender). AStA Wirtschafts- und Sozialstatistisches Archiv 2(4), 301-328.

Wilson, J. and M. Musick (1997). Who Cares? Toward an Integrated Theory of Volunteer Work. American Sociological Review 62(5), 694-713.

Wilson, J. and M. Musick (2012). The Effects of Volunteering on the Volunteer. Law and Contemporary Problems 62(4), 141-168.

Woessmann, L. (2003). Schooling Resources, Educational Institutions, and Student Performance: The International Evidence. Oxford Bulletin of Economics and Statistics 65(2), 117-170.

Woessmann, L. (2016). The Importance of School Systems: Evidence from International Differences in Student Achievement. IZA Discussion Paper 10001. 


\section{Appendix}

Figure A.1: Implementation of Reform, Variation Across States and Over Time

\section{Federal Republic of Germany}

\section{Reform}

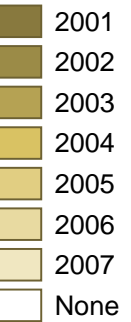

Students

Upper Track

Intermediate Track

Lower Track

Multiple Tracks

Other

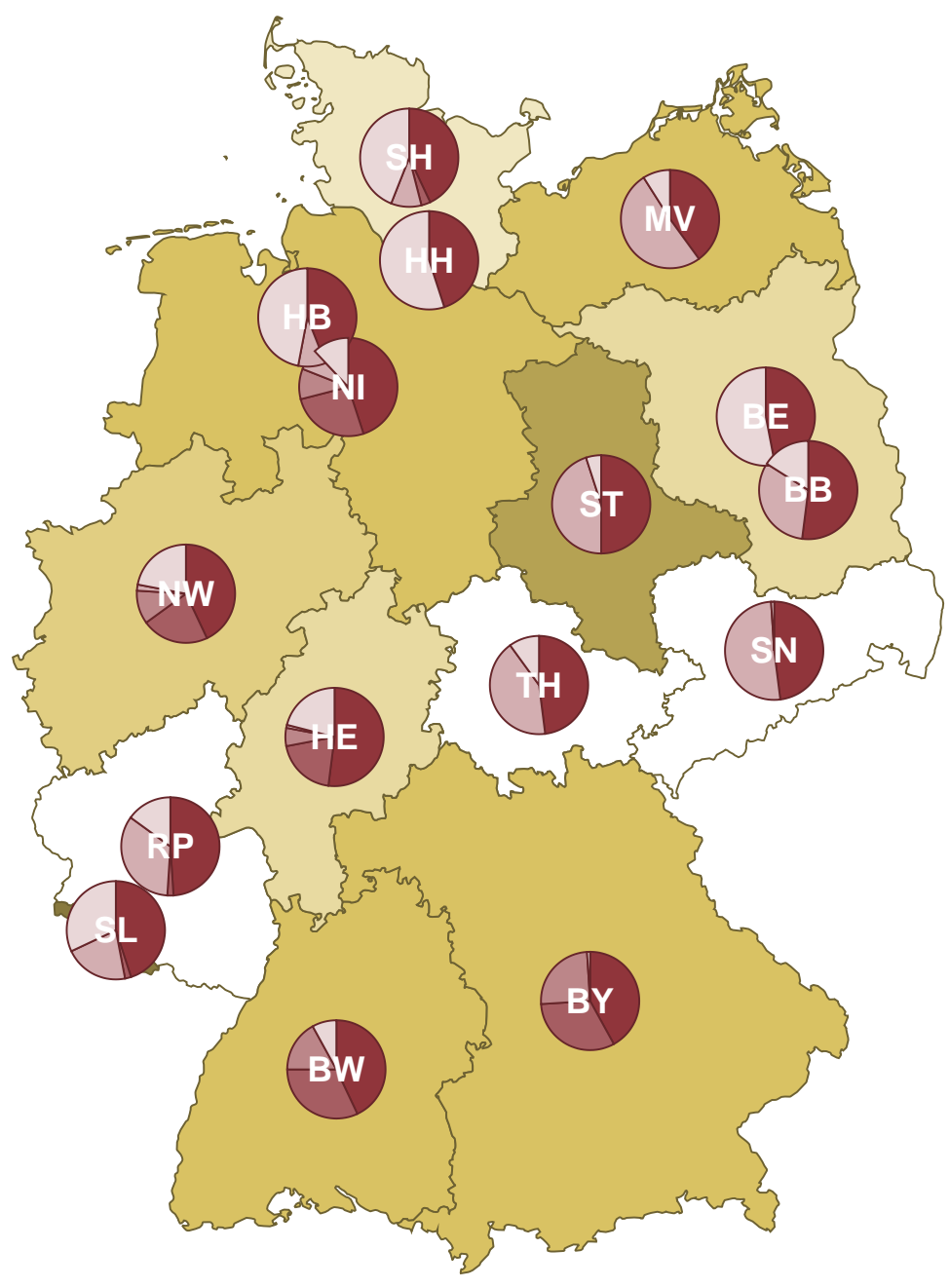

Note: The figure shows variation in the implementation of the reform across states and over time. It also reports the shares of students in the different tracks for each state, as of school year 2013/14. The category multiple tracks includes students in schools combining the intermediate and lower track; other includes students in comprehensive and Waldorf schools.

The states are Baden-Wuerttemberg (BW), Bavaria (BY), Berlin (BE), Brandenburg (BB), Bremen (HB), Hamburg (HH), Hesse (HE), Lower Saxony (NI), Mecklenburg-West Pomerania (MV), North Rhine-Westphalia (NW), Rhineland-Palatinate (RP), Saarland (SL), Saxony (SN), Saxony-Anhalt (ST), Schleswig-Holstein (SH), and Thuringia (TH).

Sources: Federal Agency for Cartography and Geodesy (2016), Federal Statistical Office (2016b), Standing Conference of the Ministers of Education and Cultural Affairs (2016), own calculations 


\section{Pro-Social Behaviour}

Figure A.2: Pro-Social Behaviour, Outside of School, Over Time

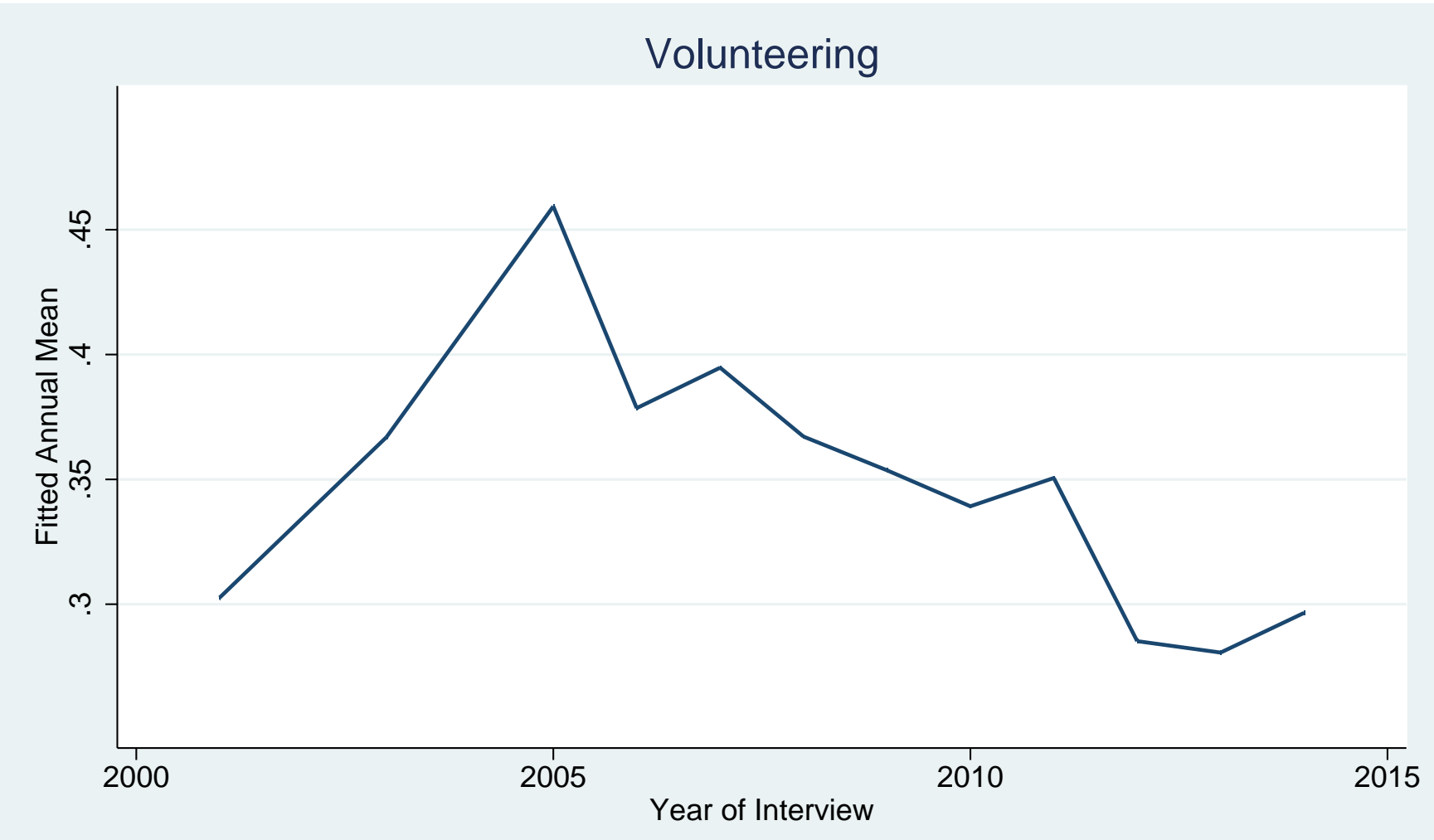

Note: The figure shows the fitted annual mean of volunteering, covariate-adjusted for demographic, educational, and parental household characteristics, as well as for sub-samples and a full set of federal state and school cohort dummy variables.

See Section 2.1 for a description of the variables used.

Source: SOEP, 2001-2014, students (upper track) aged 17 to 20, own calculations 


\section{Graphical Evidence}

Figure A.3: Graphical Evidence - Pro-Social Behaviour, Outside of School, Over Time, 1 of 2

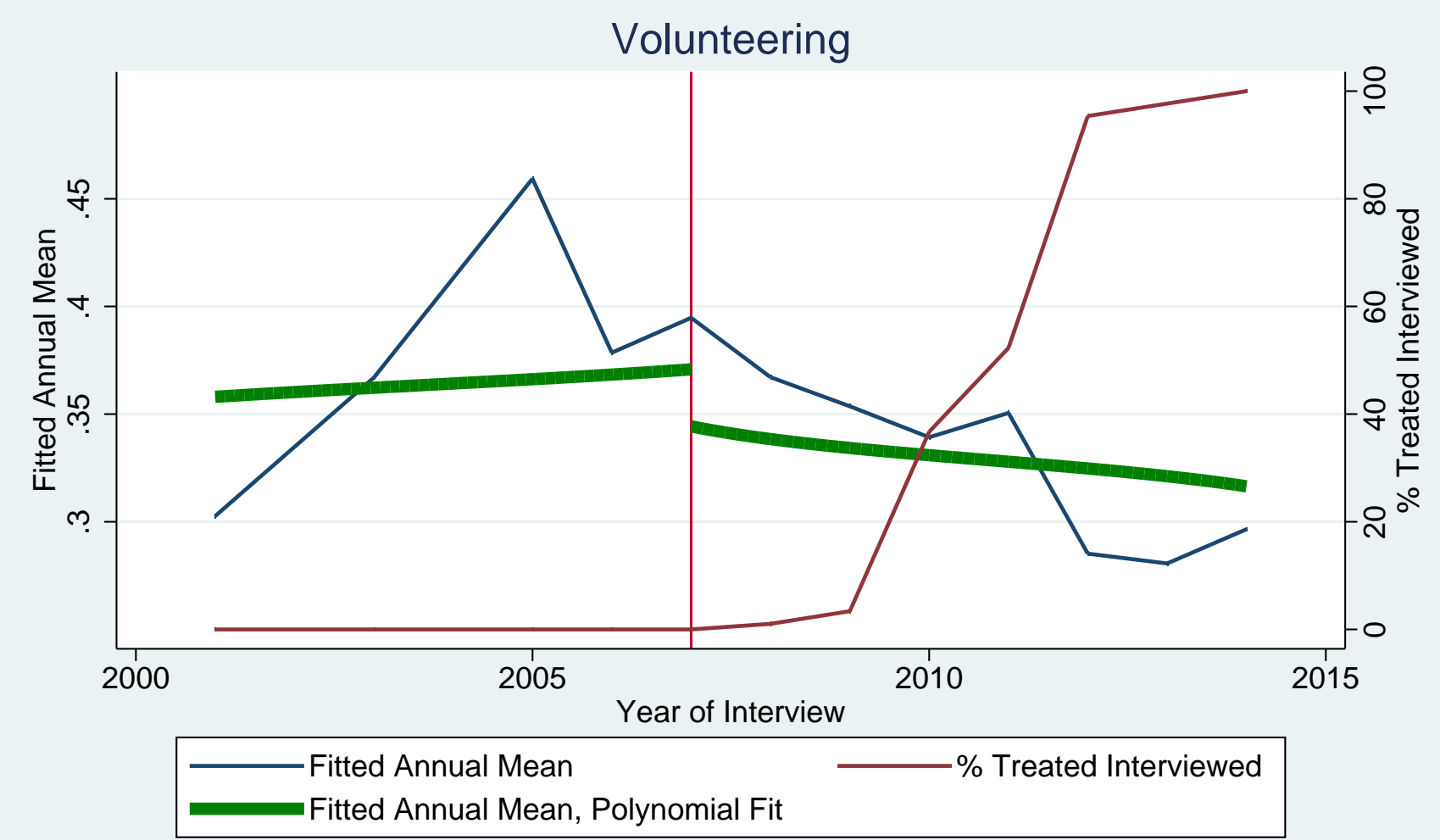

Note: The figure shows the fitted annual mean of volunteering, covariate-adjusted for demographic, educational, and parental household characteristics, as well as for sub-samples and a full set of federal state and school cohort dummy variables.

See Section 2.1 for a description of the variables used.

Source: SOEP, 2001-2014, students (upper track) aged 17 to 20, own calculations 
Figure A.4: Graphical Evidence - Pro-Social Behaviour, Outside of School, Over Time, 2 of 2

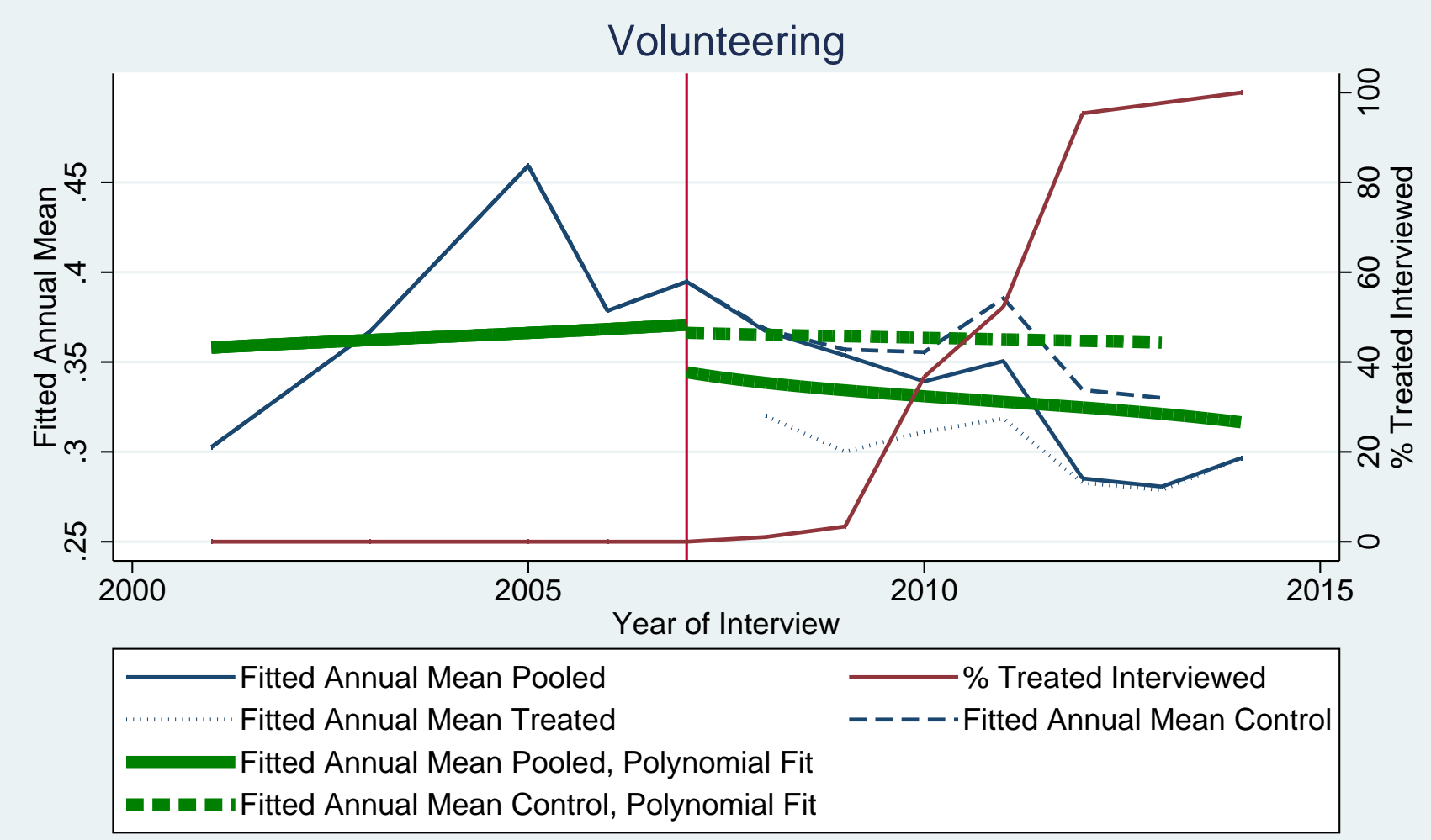

Note: The figure shows the fitted annual mean of volunteering, covariate-adjusted for demographic, educational, and parental household characteristics, as well as for sub-samples and a full set of federal state and school cohort dummy variables.

See Section 2.1 for a description of the variables used.

Source: SOEP, 2001-2014, students (upper track) aged 17 to 20, own calculations 
Figure A.5: Graphical Evidence - Pro-Social Behaviour, Outside of School, Common Trend, 1 of 2

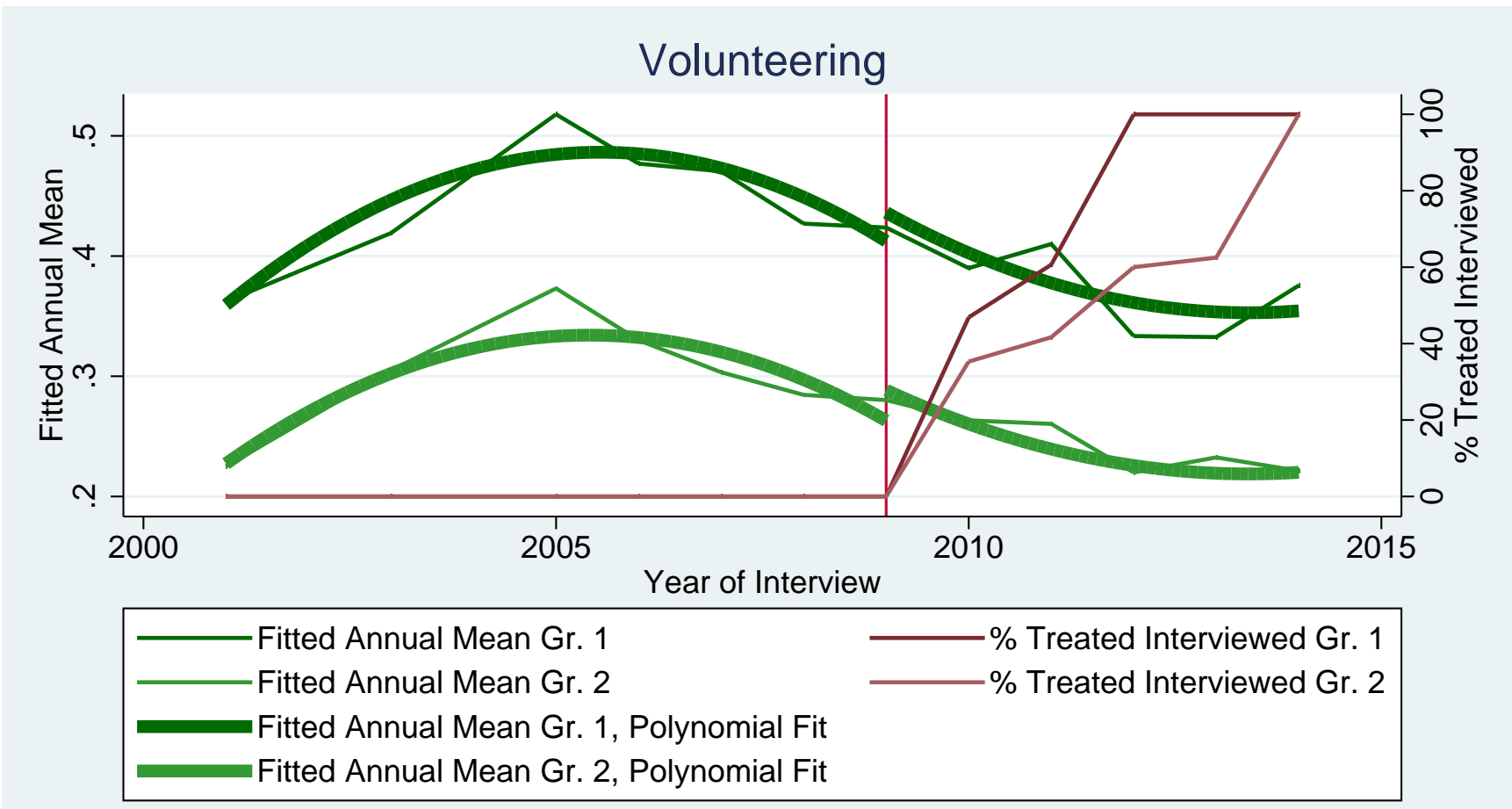

Gr. 1 includes the federal states of Baden-Wuerttemberg, Bavaria, Bremen, Hesse, and Lower Saxony. Gr. 2 includes the federal states of Berlin, Brandenburg, and Schleswig-Holstein.

Note: The figure shows the fitted annual mean of volunteering, covariate-adjusted for demographic, educational, and parental household characteristics, as well as for sub-samples and a full set of federal state and school cohort dummy variables.

See Section 2.1 for a description of the variables used.

Source: SOEP, 2001-2014, students (upper track) aged 17 to 20, own calculations 
Figure A.6: Graphical Evidence - Pro-Social Behaviour, Outside of School, Common Trend, 2 of 2

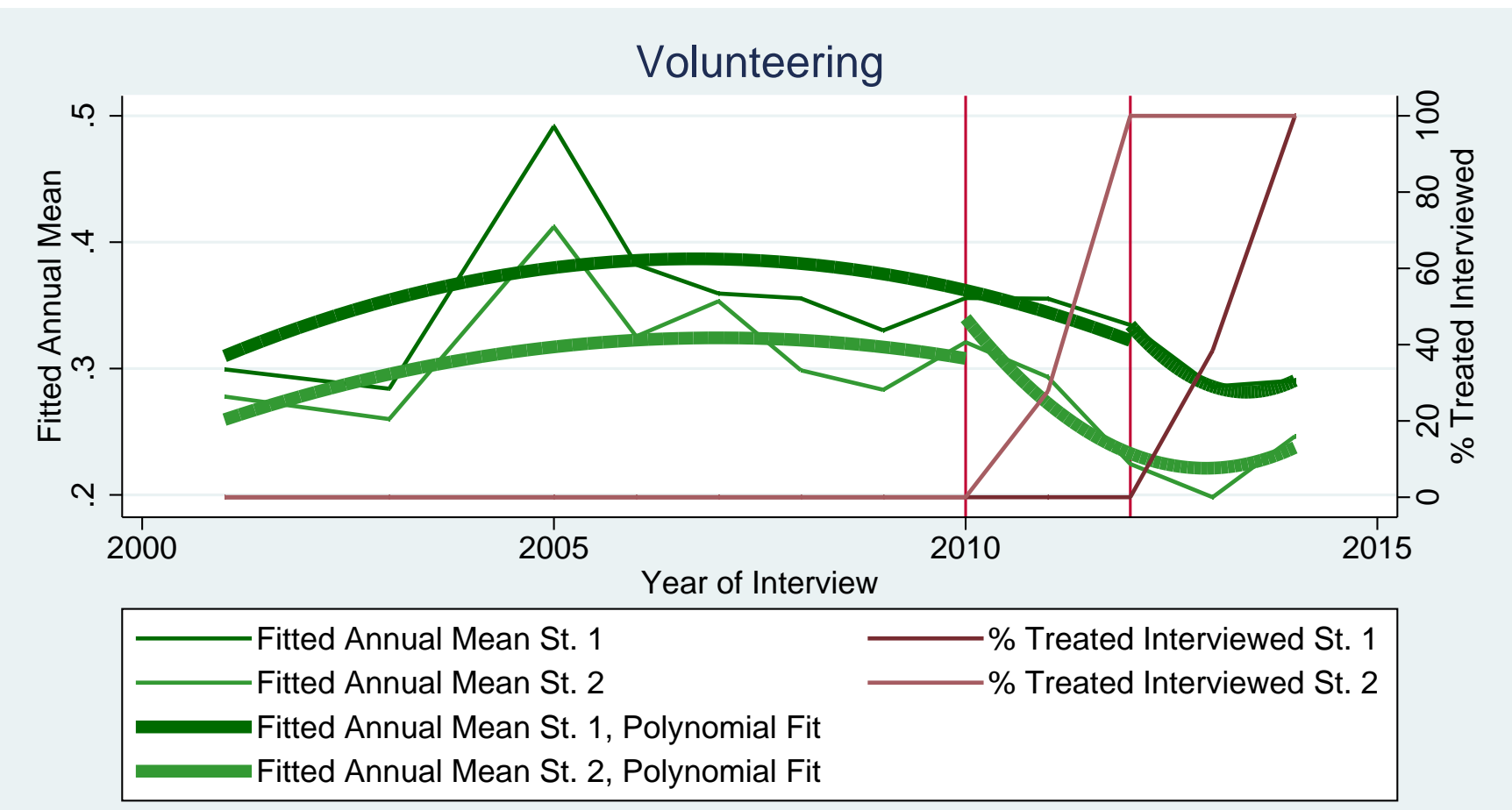

St. 1 is the federal state of Schleswig-Holstein.

St. 2 is the federal state of North Rhine-Westphalia.

Note: The figure shows the fitted annual mean of volunteering, covariate-adjusted for demographic, educational, and parental household characteristics, as well as for sub-samples and a full set of federal state and school cohort dummy variables.

See Section 2.1 for a description of the variables used.

Source: SOEP, 2001-2014, students (upper track) aged 17 to 20, own calculations 
Figure A.7: Graphical Evidence - Pro-Social Behaviour, Outside of School, Change in Distribution

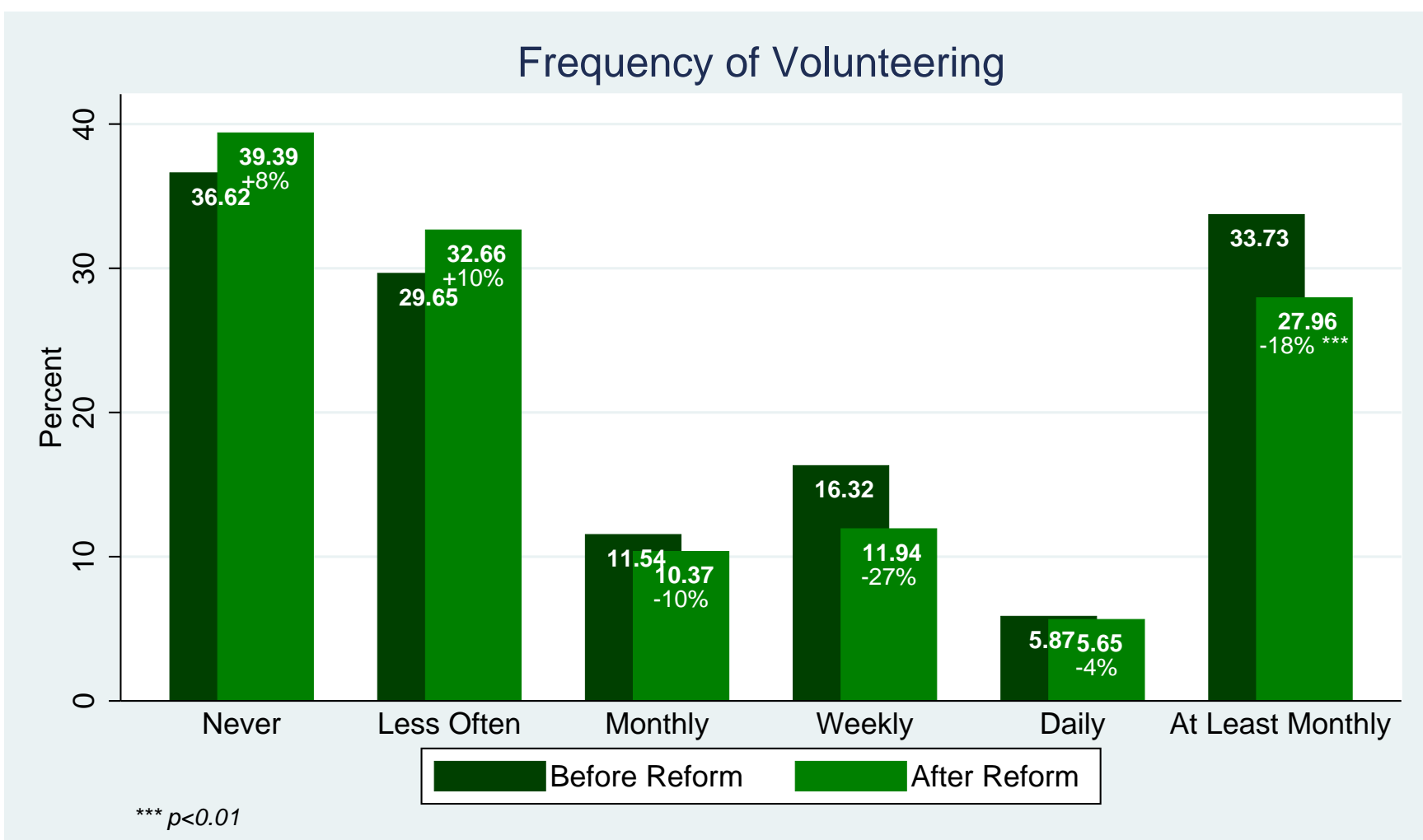

Note: The figure shows the change in the frequency distribution of volunteering due to the reform. The respective change is estimated from a separate regression in which the respective frequency of volunteering serves as the outcome. The regressions routinely control for demographic, educational, and parental household characteristics, as well as for sub-samples and for federal states and school cohorts.

See Section 2.1 for a description of the variables used.

Source: SOEP, 2001-2014, students (upper track) aged 17 to 20, own calculations 


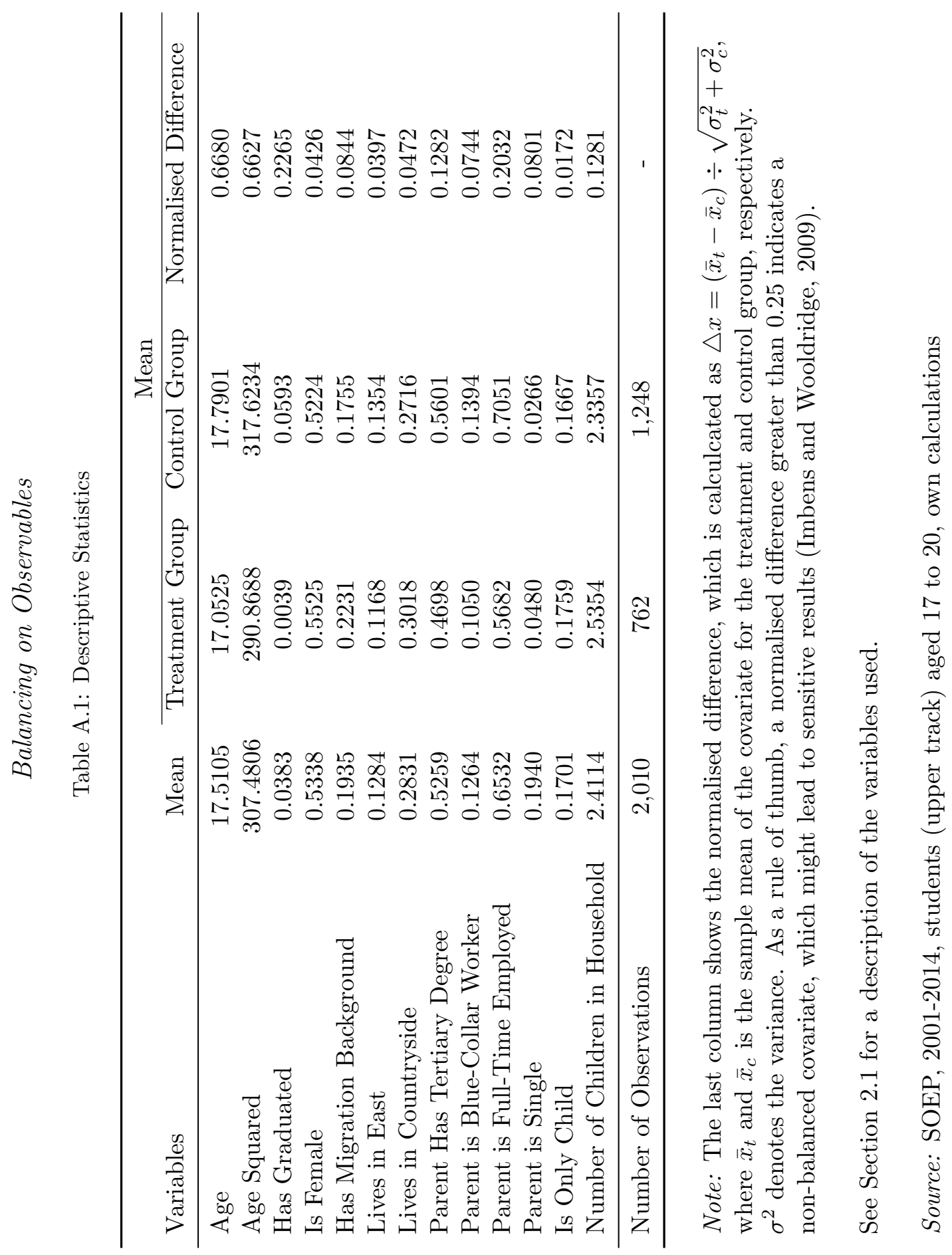




\section{Baseline Results}

Table A.2: Baseline Results - Pro-Social Behaviour, Outside of School

\begin{tabular}{lcccc}
\hline & \multicolumn{4}{c}{ Volunteering } \\
Regressors & $(1)$ & $(2)$ & $(3)$ & $(4)$ \\
\hline Reform & $-0.0661^{* * *}$ & $-0.0591^{* * *}$ & $-0.0590^{* * *}$ & $-0.0577^{* * *}$ \\
& $(0.0126)$ & $(0.0126)$ & $(0.0129)$ & $(0.0140)$ \\
Age & & 0.5343 & 0.5691 & 0.6159 \\
& & $(0.3919)$ & $(0.4324)$ & $(0.5162)$ \\
Age Squared & & -0.0139 & -0.0149 & -0.0161 \\
& & $(0.0105)$ & $(0.0116)$ & $(0.0139)$ \\
Has Graduated & & & 0.0115 & 0.0171 \\
& No & No & $(0.0310)$ & $(0.0384)$ \\
\hline Other Demographic Characteristics & No & No & No & Yes \\
Parental Characteristics & No & No & No & Yes \\
Household Characteristics & 2,010 & 2,010 & 2,010 & 2,010 \\
\hline Number of Observations & 0.0517 & 0.0532 & 0.0532 & 0.0761 \\
$\mathrm{R}^{2}$ & 0.0295 & 0.0300 & 0.0295 & 0.0482 \\
Adjusted R & & & \\
\hline
\end{tabular}

Robust standard errors clustered at the federal state level in parentheses *** $p<0.01,{ }^{* *} p<0.05,{ }^{*} p<0.1$

Note: All models include a constant, controls for sub-samples, and a full set of federal state and school cohort dummy variables. All figures are rounded to four decimal places.

See Section 2.1 for a description of the variables used.

Source: SOEP, 2001-2014, students (upper track) aged 17 to 20, own calculations 


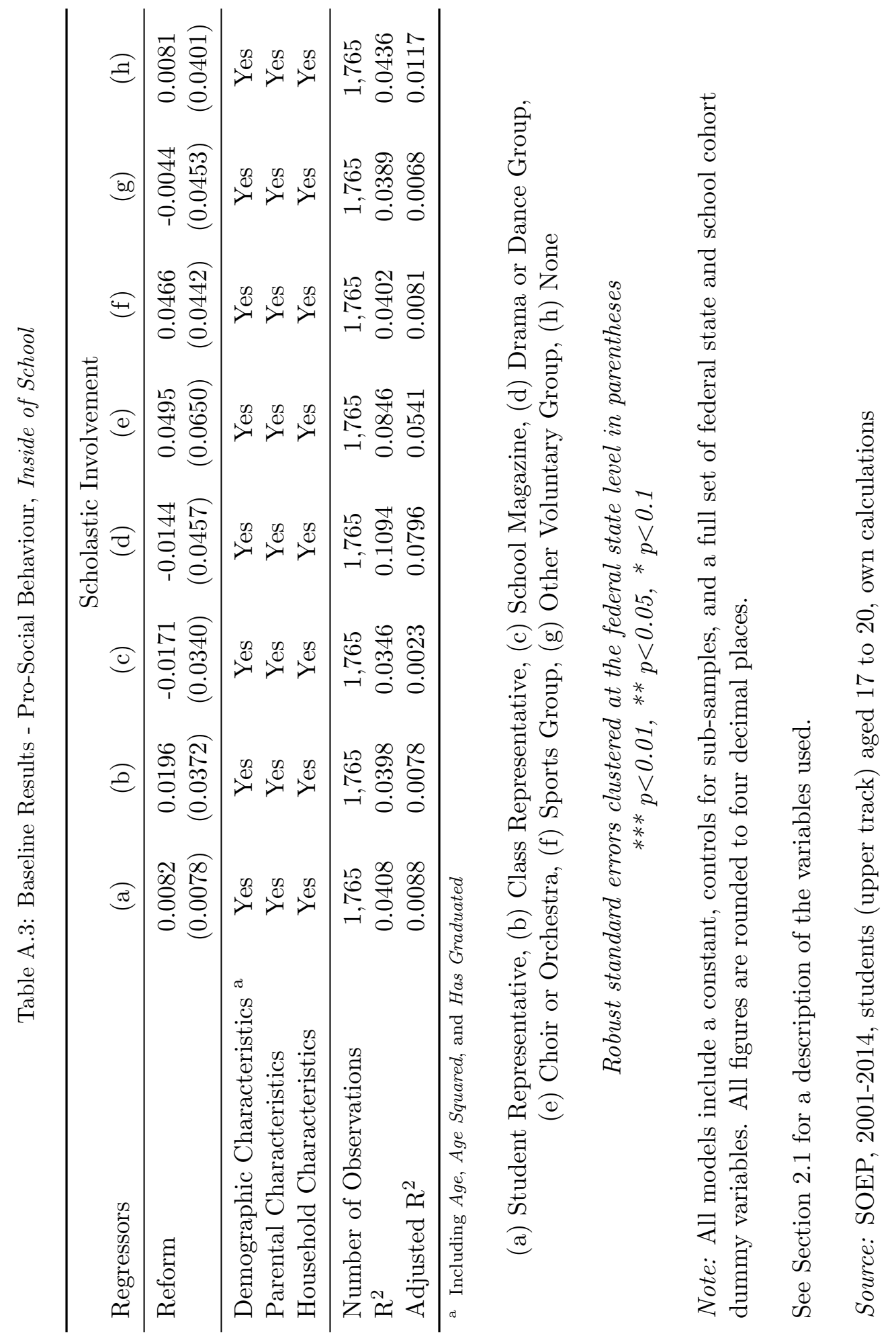


Table A.4: Baseline Results - Political Interest

\begin{tabular}{|c|c|c|c|c|}
\hline \multirow[b]{2}{*}{ Regressors } & \multicolumn{4}{|c|}{ Political Interest } \\
\hline & (a) & (b) & (c) & (d) \\
\hline Reform & -0.0366 & -0.0686 & $0.1592^{* *}$ & $-0.0539 *$ \\
\hline & $(0.0326)$ & $(0.0483)$ & $(0.0618)$ & $(0.0281)$ \\
\hline Demographic Characteristics ${ }^{a}$ & Yes & Yes & Yes & Yes \\
\hline Parental Characteristics & Yes & Yes & Yes & Yes \\
\hline Household Characteristics & Yes & Yes & Yes & Yes \\
\hline Number of Observations & 2,315 & 2,315 & 2,315 & 2,315 \\
\hline $\mathrm{R}^{2}$ & 0.0510 & 0.0592 & 0.0531 & 0.0547 \\
\hline Adjusted $\mathrm{R}^{2}$ & 0.0253 & 0.0337 & 0.0274 & 0.0291 \\
\hline
\end{tabular}

a Including Age, Age Squared, and Has Graduated

(a) Strong, (b) Fair, (c) Weak, (d) None

Robust standard errors clustered at the federal state level in parentheses *** $p<0.01$, ** $p<0.05,{ }^{*} p<0.1$

Note: All models include a constant, controls for sub-samples, and a full set of federal state and school cohort dummy variables. All figures are rounded to four decimal places.

See Section 2.1 for a description of the variables used.

Source: SOEP, 2000-2014, students (upper track) aged 17 to 20, own calculations 


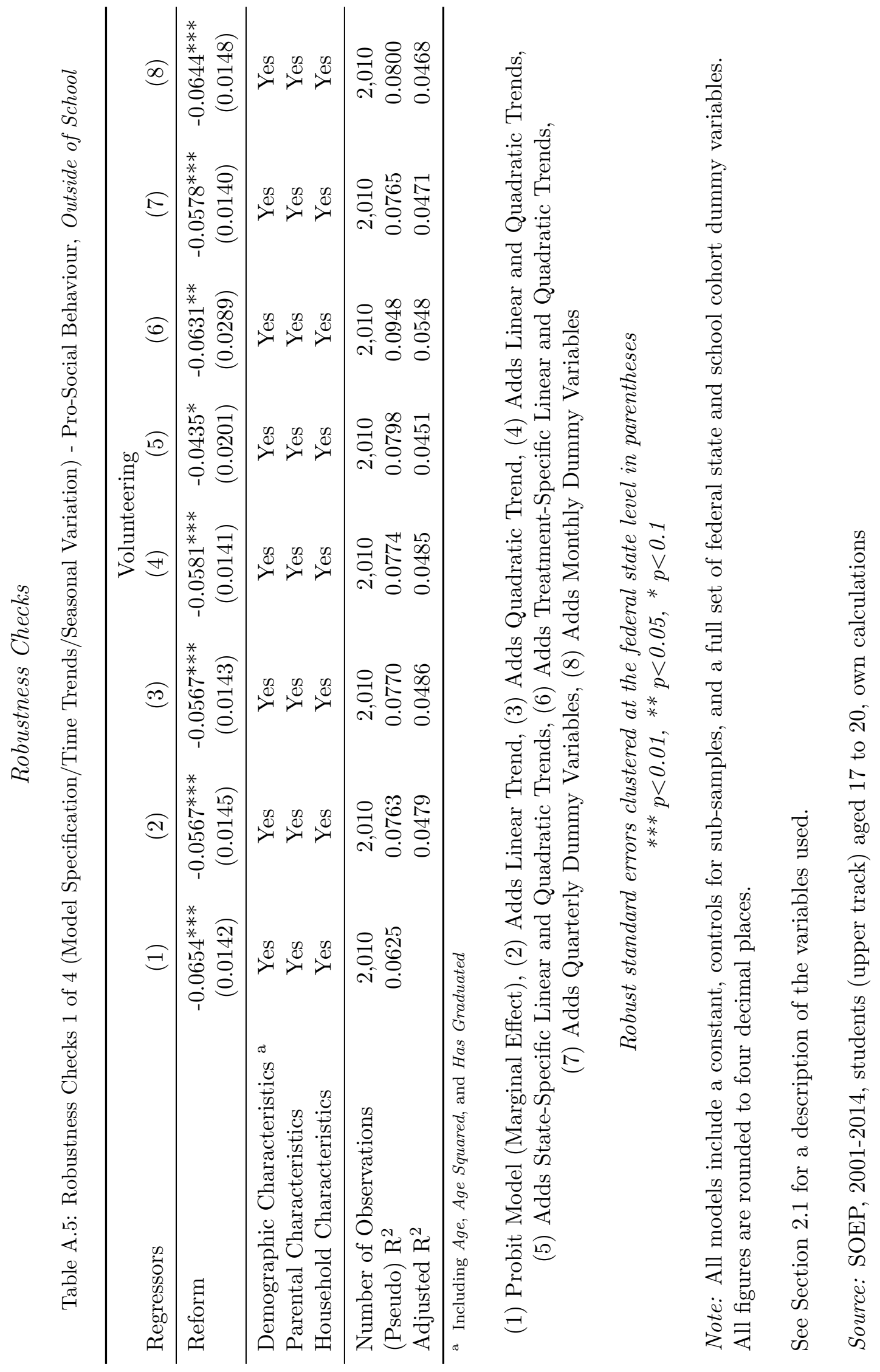




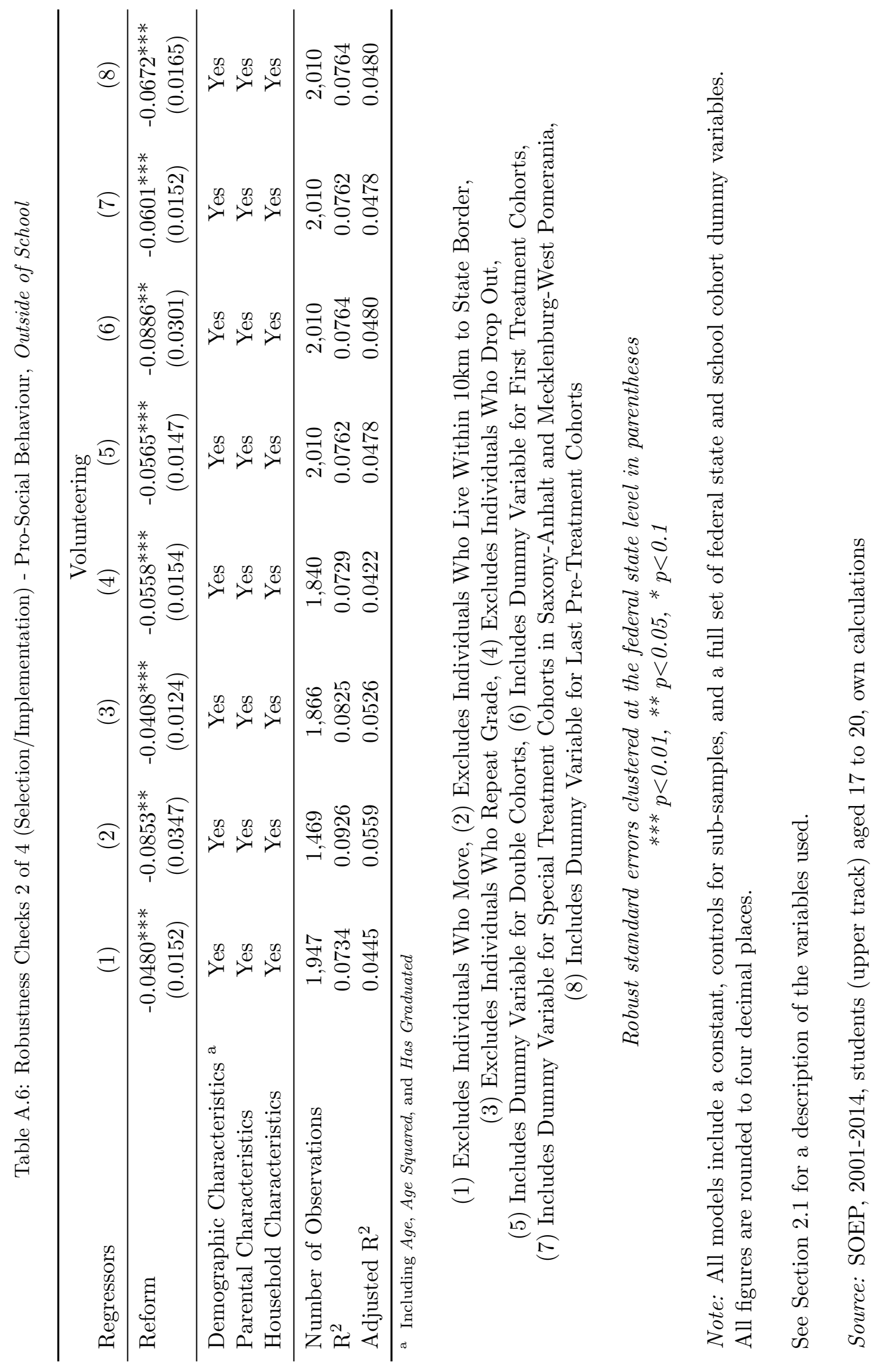


Table A.7: Robustness Checks 3 of 4 (Other Reforms) - Pro-Social Behaviour, Outside of School

\begin{tabular}{lccccc}
\hline & \multicolumn{3}{c}{ Volunteering } & $(4)$ & $(5)$ \\
\hline Regressors & $(1)$ & $(2)$ & $(3)$ & $(4)$ & $-0.0549^{* * *}$ \\
& $-0.0536^{* * *}$ & $-0.0557^{* * *}$ & $-0.0560^{* * *}$ & $-0.0577^{* * *}$ & $-0.0158)$ \\
\hline Demographic Characteristics & $(0.0167)$ & $(0.0193)$ & $(0.0135)$ & $(0.0124)$ & $(0.05$ \\
Parental Characteristics & Yes & Yes & Yes & Yes & Yes \\
Household Characteristics & Yes & Yes & Yes & Yes & Yes \\
\hline Number of Observations & Yes & Yes & Yes & Yes & Yes \\
$\mathrm{R}^{2}$ & 2,010 & 2,010 & 2,010 & 2,010 & 2,010 \\
Adjusted R $\mathrm{R}^{2}$ & 0.0762 & 0.0762 & 0.0763 & 0.0761 & 0.0765 \\
\hline
\end{tabular}

a Including Age, Age Squared, and Has Graduated

(1) Includes Dummy Variable for Changes in Central Exit Examinations,

(2) Includes Dummy Variable for Changes in Tracking at Grade Seven,

(3) Includes Dummy Variable for Changes in Two-Tier System,

(4) Includes Dummy Variable for Changes in Subject Choice,

(5) Includes Dummy Variable for Federal Volunteer Service

Robust standard errors clustered at the federal state level in parentheses *** $p<0.01$, ** $p<0.05, * p<0.1$

Note: All models include a constant, controls for sub-samples, and a full set of federal state and school cohort dummy variables. All figures are rounded to four decimal places.

See Section 2.1 for a description of the variables used.

Source: SOEP, 2001-2014, students (upper track) aged 17 to 20, own calculations 
Table A.8: Robustness Checks 4 of 4 (Placebo Tests) - Pro-Social Behaviour, Outside of School

\begin{tabular}{|c|c|c|c|c|c|}
\hline Regressors & (1) & $(2)$ & $\begin{array}{l}\text { olunteerin } \\
\text { (3) }\end{array}$ & $(4)$ & $(5)$ \\
\hline Reform & $\begin{array}{l}-0.0125 \\
(0.0305)\end{array}$ & $\begin{array}{c}-0.0254 \\
(0.0383)\end{array}$ & $\begin{array}{c}0.0026 \\
(0.0264)\end{array}$ & $\begin{array}{c}0.0216 \\
(0.0275)\end{array}$ & $\begin{array}{c}-0.0164 \\
(0.0252)\end{array}$ \\
\hline Demographic Characteristics ${ }^{a}$ & Yes & Yes & Yes & Yes & Yes \\
\hline Parental Characteristics & Yes & Yes & Yes & Yes & Yes \\
\hline Household Characteristics & Yes & Yes & Yes & Yes & Yes \\
\hline Number of Observations & 1,966 & 1,929 & 2,010 & 2,010 & 2,010 \\
\hline $\mathrm{R}^{2}$ & 0.0779 & 0.0799 & 0.0757 & 0.0760 & 0.0758 \\
\hline Adjusted $\mathrm{R}^{2}$ & 0.0493 & 0.0508 & 0.0477 & 0.0472 & 0.0479 \\
\hline
\end{tabular}

a Including Age, Age Squared, and Has Graduated

(1) Placebo School Cohorts (c-1), (2) Placebo School Cohorts (c-2), (3) Placebo School Cohorts (Random), (4) Placebo Federal States (Random),

(5) Placebo School Cohorts and Federal States (Random)

Robust standard errors clustered at the federal state level in parentheses *** $p<0.01,{ }^{* *} p<0.05,{ }^{*} p<0.1$

Note: All models include a constant, controls for sub-samples, and a full set of federal state and school cohort dummy variables. All figures are rounded to four decimal places.

See Section 2.1 for a description of the variables used.

Source: SOEP, 2001-2014, students (upper track) aged 17 to 20, own calculations 


\section{Web Appendix}

Figure W.1: Graphical Evidence - Volunteering, Over Time

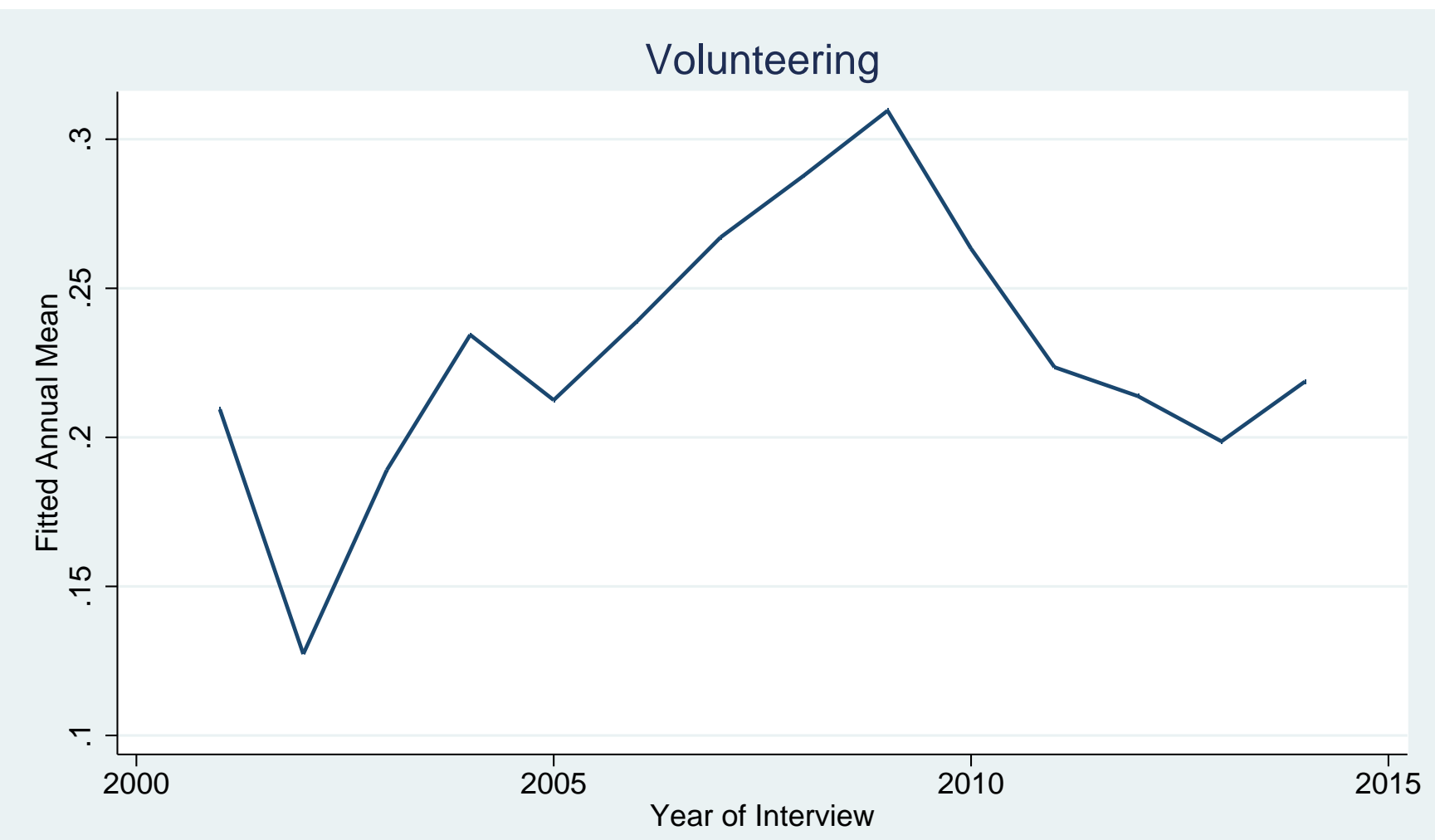

Note: The figure shows the fitted annual mean of volunteering, covariate-adjusted for demographic, educational, and parental household characteristics, as well as for sub-samples and a full set of federal state and school cohort dummy variables.

See Section 2.1 for a description of the variables used.

Source: SOEP, 2001-2014, students (lower and intermediate track) aged 17 to 20, own calculations 


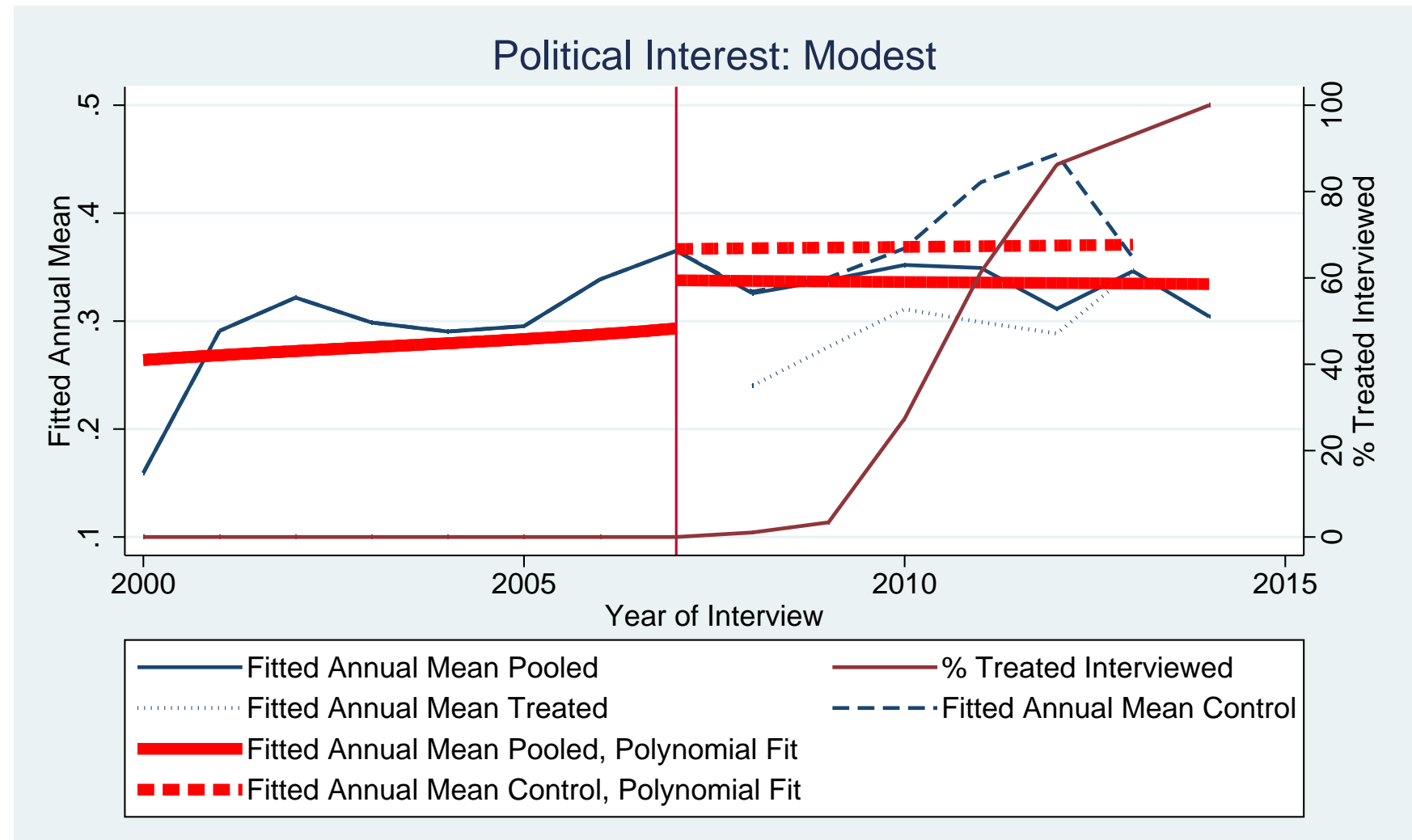

Note: The figure shows the fitted annual mean of political interest, covariate-adjusted for demographic, educational, and parental household characteristics, as well as for sub-samples and a full set of federal state and school cohort dummy variables.

See Section 2.1 for a description of the variables used.

Source: SOEP, 2001-2014, students (upper track) aged 17 to 20, own calculations 
Figure W.3: Graphical Evidence - Political Interest, Common Trend

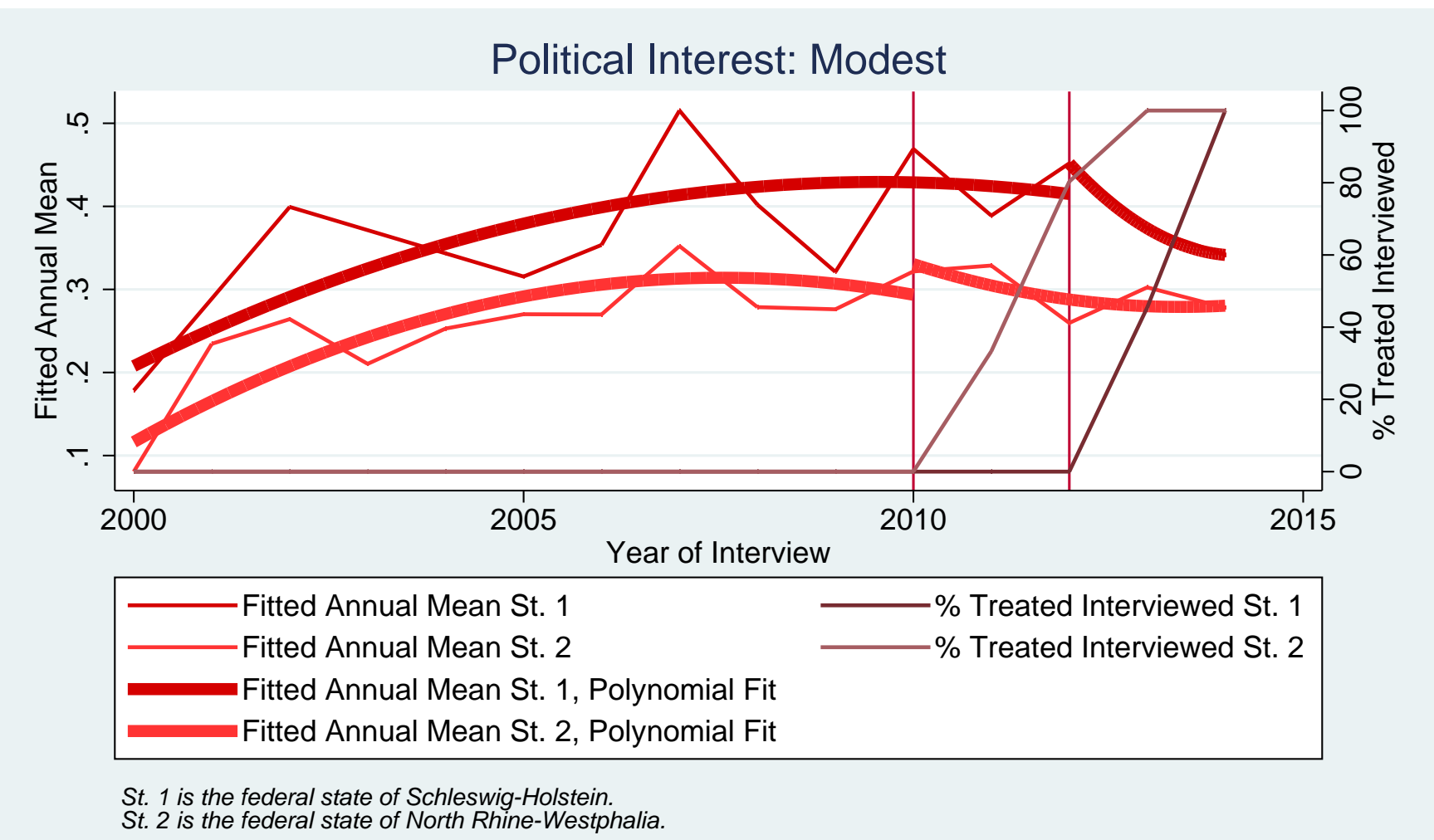

Note: The figure shows the fitted annual mean of political interest, covariate-adjusted for demographic, educational, and parental household characteristics, as well as for sub-samples and a full set of federal state and school cohort dummy variables.

See Section 2.1 for a description of the variables used.

Source: SOEP, 2001-2014, students (upper track) aged 17 to 20, own calculations 


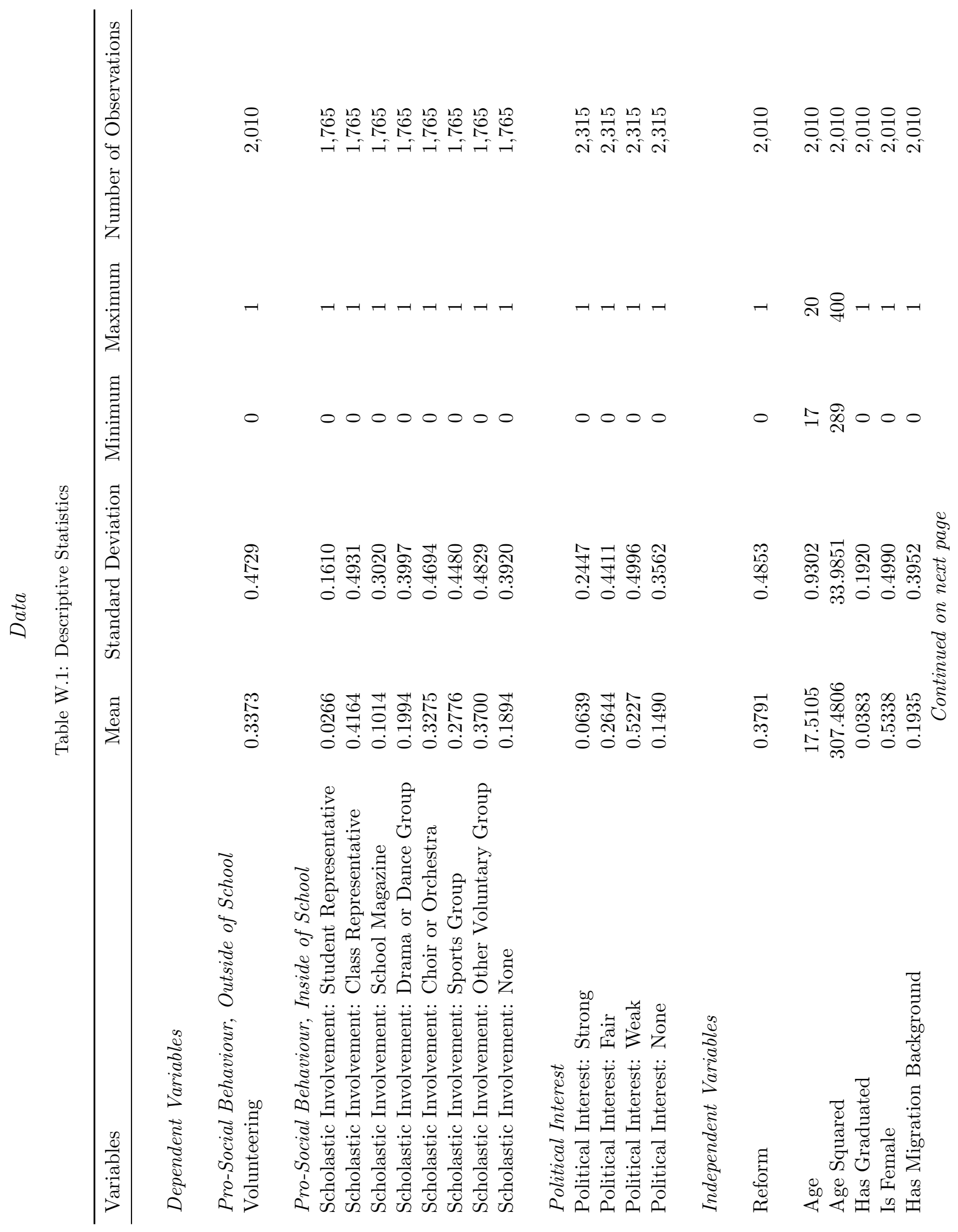




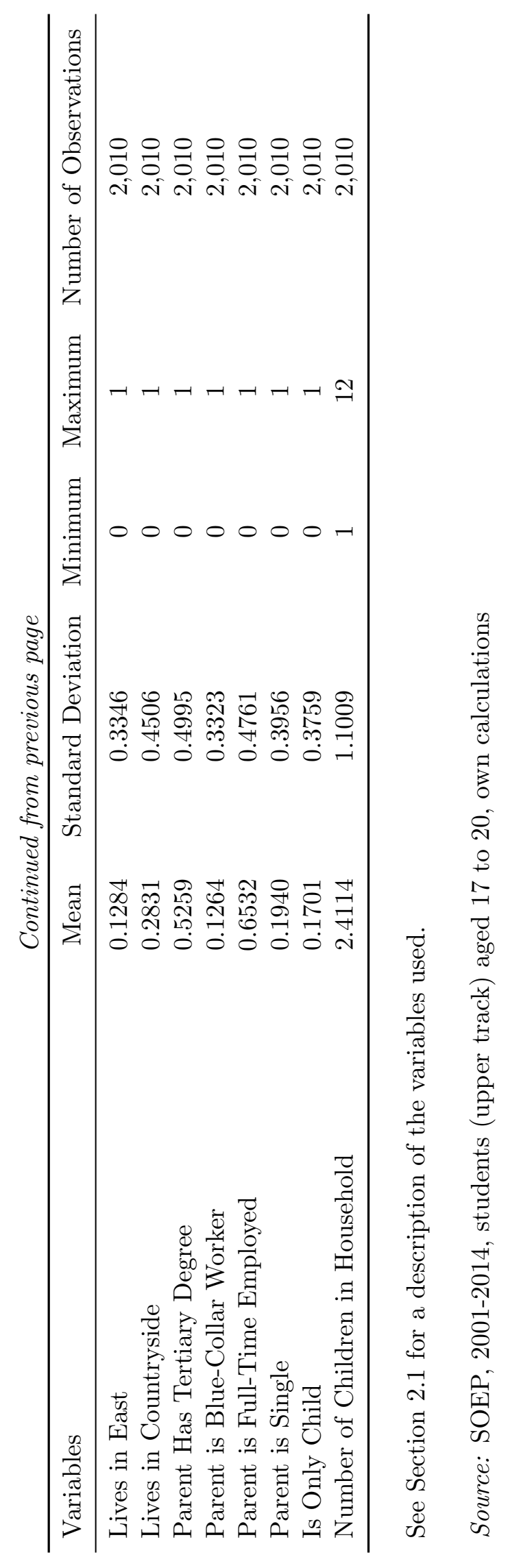




\section{Baseline Results}

Table W.2: Baseline Results - Pro-Social Behaviour, Outside of School

\begin{tabular}{|c|c|c|c|c|}
\hline \multirow[b]{2}{*}{ Regressors } & \multicolumn{4}{|c|}{ Volunteering } \\
\hline & (1) & $(2)$ & $(3)$ & $(4)$ \\
\hline Reform & $\begin{array}{c}-0.0661^{* * *} \\
(0.0126)\end{array}$ & $\begin{array}{c}-0.0591^{* * *} \\
(0.0126)\end{array}$ & $\begin{array}{c}-0.0590^{* * *} \\
(0.0129)\end{array}$ & $\begin{array}{c}-0.0577^{* * *} \\
(0.0140)\end{array}$ \\
\hline Age & & $\begin{array}{c}0.5343 \\
(0.3919)\end{array}$ & $\begin{array}{c}0.5691 \\
(0.4324)\end{array}$ & $\begin{array}{c}0.6159 \\
(0.5162)\end{array}$ \\
\hline Age Squared & & $\begin{array}{l}-0.0139 \\
(0.0105)\end{array}$ & $\begin{array}{l}-0.0149 \\
(0.0116)\end{array}$ & $\begin{array}{l}-0.0161 \\
(0.0139)\end{array}$ \\
\hline Has Graduated & & & $\begin{array}{c}0.0115 \\
(0.0310)\end{array}$ & $\begin{array}{c}0.0171 \\
(0.0384)\end{array}$ \\
\hline Is Female & & & & $\begin{array}{l}-0.0213 \\
(0.0244)\end{array}$ \\
\hline Has Migration Background & & & & $\begin{array}{c}-0.0831^{*} \\
(0.0417)\end{array}$ \\
\hline Lives in East & & & & $\begin{array}{c}-0.1753^{\text {*** }} \\
(0.0326)\end{array}$ \\
\hline Lives in Countryside & & & & $\begin{array}{c}0.0034 \\
(0.0269)\end{array}$ \\
\hline Parent Has Tertiary Degree & & & & $\begin{array}{c}0.0600 * * \\
(0.0200)\end{array}$ \\
\hline Parent is Blue-Collar Worker & & & & $\begin{array}{c}-0.0888^{* *} \\
(0.0326)\end{array}$ \\
\hline Parent is Full-Time Employed & & & & $\begin{array}{c}0.0068 \\
(0.0191)\end{array}$ \\
\hline Parent is Single & & & & $\begin{array}{c}-0.0702^{* * *} \\
(0.0173)\end{array}$ \\
\hline Is Only Child & & & & $\begin{array}{l}-0.0024 \\
(0.0385)\end{array}$ \\
\hline Number of Children in Household & & & & $\begin{array}{c}0.0211 \\
(0.0137)\end{array}$ \\
\hline Number of Observations & 2,010 & 2,010 & 2,010 & 2,010 \\
\hline $\mathrm{R}^{2}$ & 0.0517 & 0.0532 & 0.0532 & 0.0761 \\
\hline Adjusted $\mathrm{R}^{2}$ & 0.0295 & 0.0300 & 0.0295 & 0.0482 \\
\hline
\end{tabular}

Robust standard errors clustered at the federal state level in parentheses *** $p<0.01,{ }^{* *} p<0.05,{ }^{*} p<0.1$

Note: All models include a constant, controls for sub-samples, and a full set of federal state and school cohort dummy variables. All figures are rounded to four decimal places.

See Section 2.1 for a description of the variables used.

Source: SOEP, 2001-2014, students (upper track) aged 17 to 20, own calculations 
Table W.3: Baseline Results - Political Interest

\begin{tabular}{lc}
\hline Regressors & $\begin{array}{c}\text { Political Interest } \\
\text { Modest }\end{array}$ \\
\hline Reform & $-0.1053^{*}$ \\
& $(0.0523)$ \\
\hline Demographic Characteristics $^{\mathrm{a}}$ & Yes \\
Parental Characteristics & Yes \\
Household Characteristics & Yes \\
\hline Number of Observations & 2,315 \\
$\mathrm{R}^{2}$ & 0.0965 \\
Adjusted $\mathrm{R}^{2}$ & 0.0721 \\
\hline
\end{tabular}

a Including Age, Age Squared, and Has Graduated

Robust standard errors clustered at the federal state level in parentheses *** $p<0.01$, ** $p<0.05, * p<0.1$

Note: All models include a constant, controls for sub-samples, and a full set of federal state and school cohort dummy variables. All figures are rounded to four decimal places.

See Section 2.1 for a description of the variables used.

Source: SOEP, 2000-2014, students (upper track) aged 17 to 20, own calculations 


\section{Robustness Checks}

Table W.4: Robustness Checks (1/2) - Pro-Social Behaviour, Outside of School

\begin{tabular}{|c|c|c|c|c|c|}
\hline Regressors & (1) & $(2)$ & $\begin{array}{l}\text { olunteering } \\
\text { (3) }\end{array}$ & (4) & $(5)$ \\
\hline Reform & $\begin{array}{c}-0.0660^{* * *} \\
(0.0188)\end{array}$ & $\begin{array}{c}-0.0577^{* * *} \\
(0.0116)\end{array}$ & $\begin{array}{c}-0.1753^{* *} \\
(0.0660)\end{array}$ & $\begin{array}{c}-0.0459^{*} \\
(0.0226)\end{array}$ & $\begin{array}{c}-0.1007^{* * *} \\
(0.0345)\end{array}$ \\
\hline Cohort 1 & & & & & $\begin{array}{c}0.0540 \\
(0.0545)\end{array}$ \\
\hline \multicolumn{6}{|l|}{ Cohort 2} \\
\hline Cohort 3 & & & & & $\begin{array}{c}0.0385 \\
(0.0403)\end{array}$ \\
\hline Cohort 4 & & & & & $\begin{array}{l}-0.0041 \\
(0.0618)\end{array}$ \\
\hline Cohort $\geq 5$ & & & & & $\begin{array}{c}0.0032 \\
(0.0667)\end{array}$ \\
\hline Demographic Characteristics ${ }^{a}$ & Yes & Yes & Yes & Yes & Yes \\
\hline Parental Characteristics & Yes & Yes & Yes & Yes & Yes \\
\hline Household Characteristics & Yes & Yes & Yes & Yes & Yes \\
\hline Number of Observations & 2,010 & 2,010 & 2,010 & 2,010 & 2,010 \\
\hline $\mathrm{R}^{2}$ & 0.0765 & 0.0761 & 0.0773 & 0.0769 & 0.0768 \\
\hline Adjusted $\mathrm{R}^{2}$ & 0.0485 & 0.0766 & 0.0475 & 0.0465 & 0.0469 \\
\hline
\end{tabular}

a Including Age, Age Squared, and Has Graduated

(1) Uses Weights,

(2) Uses Bootstrapped Standard Errors,

(3) Includes All Dummy Variables From 5 to 8 in Table A.5.

(4) Includes All Dummy Variables From 1 to 5 in Table A.6.

(5) Adds Cohort Dummy Variables

Robust standard errors clustered at the federal state level in parentheses *** $p<0.01$, ** $p<0.05,{ }^{*} p<0.1$

Note: All models include a constant, controls for sub-samples, and a full set of federal state and school cohort dummy variables. All figures are rounded to four decimal places.

See Section 2.1 for a description of the variables used.

Source: SOEP, 2001-2014, students (upper track) aged 17 to 20, own calculations 
Table W.5: Robustness Checks (2/2) - Pro-Social Behaviour, Outside of School

\begin{tabular}{lccc}
\hline Regressors & \multicolumn{3}{c}{ Probability } \\
\hline Reform & (a) & $(\mathrm{b})$ & $(\mathrm{c})$ \\
& 0.0167 & 0.0386 & -0.0133 \\
& $(0.0130)$ & $(0.0333)$ & $(0.0238)$ \\
\hline Demographic Characteristics $^{\mathrm{a}}$ & Yes & Yes & Yes \\
Parental Characteristics $_{\text {Household Characteristics }}$ & Yes & Yes & Yes \\
\hline Number of Observations & Yes & Yes & Yes \\
$\mathrm{R}^{2}$ & 2,010 & 2,010 & 2,010 \\
Adjusted $\mathrm{R}^{2}$ & 0.0583 & 0.0785 & 0.2900 \\
\hline
\end{tabular}

a Including Age, Age Squared, and Has Graduated

(a) Moving, (b) Repeating Grade, (c) Dropping Out

Robust standard errors clustered at the federal state level in parentheses *** $p<0.01, * * p<0.05, * p<0.1$

Note: All models include a constant, controls for sub-samples, and a full set of federal state and cohort dummy variables. All figures are rounded to four decimal places.

See Section 2.1 for a description of the variables used.

Source: SOEP, 2001-2014, students (upper track) aged 17 to 20 , own calculations 